\title{
Traumatic Brain Injury Diminishes Feedforward Activation of Parvalbumin-Expressing Interneurons in the Dentate Gyrus
}

\author{
Kaitlin A. Folweiler, ${ }^{1,2,3}$ Guoxiang Xiong, ${ }^{1,2}$ Kaitlin M. Best, ${ }^{1,2}$ Hannah E. Metheny, ${ }^{1,2}$ Gabriel Nah, ${ }^{1,2}$ and \\ (D)Akiva S. Cohen ${ }^{1,2,3}$
}

https://doi.org/10.1523/ENEURO.0195-19.2020

${ }^{1}$ Department of Anesthesiology and Critical Care Medicine, Children's Hospital of Philadelphia, Philadelphia, PA 19104, ${ }^{2}$ Department of Anesthesiology and Critical Care, Perelman School of Medicine, University of Pennsylvania, Philadelphia, PA 19104, and ${ }^{3}$ Neuroscience Graduate Group, University of Pennsylvania, Philadelphia, PA 19104

\begin{abstract}
Traumatic brain injury (TBI) is associated with aberrant network hyperexcitability in the dentate gyrus (DG). $\mathrm{GABA}_{A}$ ergic parvalbumin-expressing interneurons (PV-INs) in the DG regulate network excitability with strong, perisomatic inhibition, although the posttraumatic effects on PV-IN function after TBI are not well understood. In this study, we investigated physiological alterations in PV-INs one week after mild lateral fluid percussion injury (LFPI) in mice. PV-IN cell loss was observed in the dentate hilus after LFPI, with surviving PV-INs showing no change in intrinsic membrane properties. Whole-cell voltage clamp recordings in PV-INs revealed alterations in both EPSCs and IPSCs (EPSCs/IPSCs). Evoked EPSCs (eEPSCs) in PV-INs from perforant path electrical stimulation were diminished after injury but could be recovered with application of a $G_{A B A} A_{A}$-receptor antagonist. Furthermore, current-clamp recordings using minimal perforant path stimulation demonstrated a decrease in evoked PV-IN action potentials (APs) after LFPI, which could be restored by blocking GABA $A_{A} e$ rgic inhibition. Together, these findings suggest that injury alters synaptic input onto PV-INs, resulting in a net inhibitory effect that reduces feedforward PV-IN activation in the DG. Decreased PV-IN activation suggests a potential mechanism of DG network hyperexcitability contributing to hippocampal dysfunction after TBI.
\end{abstract}

Key words: basket cells; dentate gyrus; hippocampus; interneurons; parvalbumin; traumatic brain injury

\section{Significance Statement}

Traumatic brain injury (TBI) damages the hippocampus and causes long-lasting memory deficits. After TBI, the dentate gyrus (DG), a crucial regulator of cortical input to the hippocampus, undergoes a dysfunctional net increase in excitation, although the circuit mechanisms underlying this network excitatory-inhibitory (E/I) imbalance are unclear. In this study, we found that TBI alters synaptic inputs onto an inhibitory interneuron population [parvalbumin (PV)-INs) in the DG which results in the decreased firing activity of these neurons because of a net inhibitory influence. The inhibition of PV-INs demonstrates a potential mechanism contributing to DG network hyperexcitability and hippocampal dysfunction after TBI.

\footnotetext{
Received May 21, 2019; accepted September 20, 2020; First published October 26, 2020

The authors declare no competing financial interests.

Author contributions: A.S.C. and K.A.F. designed research; A.S.C., G.X., K.M.B., H.E.M., G.N., and K.A.F. performed research; A.S.C., G.X., K.M.B., G.N., and K.A.F. analyzed data; A.S.C., G.X., and K.A.F. wrote the paper.

A.S.C. was supported by the National Institutes of Health National Institute of Child Health and Human Development R37 HD059288 and by a grant from the Pennsylvania Department of Health.
}

Acknowledgements: We thank Dr. Eric Marsh of Children's Hospital of Philadelphia for gift of transgenic mice.

Correspondence can be directed to Akiva S. Cohen at cohena@email. chop.edu.

https://doi.org/10.1523/ENEURO.0195-19.2020

Copyright (C) 2020 Folweiler et al.

This is an open-access article distributed under the terms of the Creative Commons Attribution 4.0 International license, which permits unrestricted use, distribution and reproduction in any medium provided that the original work is properly attributed. 


\section{Introduction}

Fast-spiking, parvalbumin-expressing GABAergic interneurons (PV-INs) are powerful regulators of excitability in neural networks and play an important role in mediating hippocampal-dependent cognitive behaviors (Freund and Buzsáki, 1996; Nitz and McNaughton, 2004; Fuchs et al., 2007; Armstrong and Soltesz, 2012; Hu et al., 2014). In the hippocampus, PV-INs contribute to the ability of the dentate gyrus (DG) subregion to act as a filter or gate of incoming sensory information from the cortex by providing strong feedforward inhibition onto granule cells (Coulter and Carlson, 2007). In combination with the low intrinsic membrane excitability of granule cells, PV-IN GABAergic inhibition contributes to sparse granule cell action potential (AP) firing under normal conditions (Ewell and Jones, 2010; Kraushaar and Jonas, 2000).

After traumatic brain injury (TBI), the DG experiences network hyperexcitability (Lowenstein et al., 1992; Toth et al., 1997; Santhakumar et al., 2000; Witgen et al., 2005). Granule cells no longer sparsely fire APs, and evoked extracellular burst discharges are increased in the granule cell layer in vivo (Lowenstein et al., 1992). This shift toward a hyperexcitable network state leads to a break down in the physiological filtering function of the $D G$ and is associated with spatial memory impairments (Folweiler et al., 2018).

One week after TBI, the frequency of miniature IPSCs (mIPSCs) is reduced in granule cells, suggesting that a loss of synaptic inhibition is contributing to granule cell hyperexcitability (Toth et al., 1997; Witgen et al., 2005). While previous studies have looked at other populations of dentate inhibitory interneurons after TBI (Hunt et al., 2011; Butler et al., 2017), the potential role of PV-INs in dentate network hyperexcitability after injury has yet to be examined. In order to understand the effects of TBI on PV-IN inhibition, we investigated the intrinsic membrane properties and synaptic inputs of PV-INs in the DG one week after mild lateral fluid percussion injury (LFPI).

\section{Materials and Methods}

\section{Mice}

All experiments were performed in accordance with protocols approved by our institution's Institutional Animal Care and Use Committee and the guidelines established by the United States Public Health Service's Guide for the Care and Use of Laboratory Animals. Experiments were designed to minimize the number of animals required and those used were cared for, handled, and medicated as appropriate to minimize their suffering. To visually identify PVINs, PVCRE transgenic mice, expressing Cre-recombinase in PV-expressing neurons (129P2 ${ }^{\text {Pvalbtm1(cre)Arbr } / J \text {; The }}$ Jackson Laboratory; RRID:IMSR_JAX:008069) were crossed with tdTomato reporter mice (129S6-Gt (ROSA)26Sor ${ }^{m 14(C A G-t d T o m a t o) H z e} / \mathrm{J}$; The Jackson Laboratory, RRID:IMSR_JAX:007908) to generate PVCRE; tdTomato +/- (i.e., PV-Tomato) transgenic animals which express tdTomato fluorescence in parvalbumin-positive $(\mathrm{PV}+)$ cells. All experiments were performed on six- to
Table 1: Male and female mice per group used in each experiment

\begin{tabular}{lclcl}
\hline & \multicolumn{2}{c}{ Sham } & \multicolumn{2}{c}{ LFPI } \\
Experiment & Male $(n)$ & Female $(n)$ & Male $(n)$ & Female $(n)$ \\
\hline Immunostaining & 3 & 0 & 4 & 0 \\
Cell counts & 6 & 2 & 4 & 5 \\
Timm staining & 10 & 0 & 10 & 0 \\
fEPSPs & 4 & 2 & 3 & 3 \\
Intrinsic properties & 5 & 5 & 4 & 6 \\
mEPSCs & 4 & 3 & 3 & 3 \\
eEPSCs & 7 & 5 & 8 & 3 \\
mIPSCs & 2 & 4 & 5 & 2 \\
Evoked APs & 3 & 2 & 3 & 2 \\
\end{tabular}

For each experiment (left column) the sample size of male and female mice in sham and LFPI groups. $n$, sample size.

eight-week-old male and female PV-Tomato mice. The primary purpose of using both male and female mice was to use all transgenic animals that were bred for experiments with the secondary aim of reducing sex bias by favoring one sex over another (Will et al., 2017). The number of male and female mice in each group is listed by experiment in Table 1.

\section{Surgical procedures}

Animals were anesthetized with a mixture of ketamine $(2.6 \mathrm{mg} / \mathrm{kg})$ and xylazine $(0.16 \mathrm{mg} / \mathrm{kg})$ via intraperitoneal injection. Once fully anesthetized, animals were placed in a stereotaxic frame (Stoetling), the scalp was incised and pulled away to fully expose the right parietal bone. An ultrathin Teflon disk, with the outer diameter equal to the inner diameter of a trephine was glued to the skull with Vetbond ( $3 \mathrm{M}$ ) between lambda and bregma sutures, and between the sagittal suture and the lateral ridge over the right hemisphere. Guided by the Teflon disk, a trephine was used to perform a 3-mm diameter craniectomy over the right parietal area. Following craniectomy, a Luer-lock needle hub (3-mm inner diameter) was secured above the skull opening with superglue (Loctite) and dental acrylic, filled with saline and capped. Lastly, animals were removed from stereotaxis, placed on a heating pad until fully recovered from anesthesia, and then returned to their respective home cage.

\section{LFPI}

Twenty-four hours after craniectomy, animals were placed under isoflurane anesthesia $\left(2 \% \mathrm{O}_{2}\right.$ in $\left.500 \mathrm{ml} / \mathrm{min}\right)$ in a chamber and respiration was visually monitored until animals reached a surgical plane of anesthesia (one respiration per $2 \mathrm{~s}$ ). At this point, animals were removed from isoflurane, the needle hub was refilled with saline and connected to the fluid percussion injury device (Department of Biomedical Engineering, Virginia Commonwealth University, Richmond, VA) via high-pressure tubing. The animal was placed onto a heating pad on its left side and on resumption of normal breathing pattern but before sensitivity to stimulation, the injury was induced by a $20-\mathrm{ms}$ pulse of saline onto the intact dura. The pressure transduced onto the dura was monitored with an oscilloscope, with injury severity ranging between 1.4 and 1.6 atmospheres (atm). Immediately after 
injury, the hub was removed from the skull and the animal was placed in a supine position to assess righting reflex. After righting, the animal was subjected to inhaled isoflurane to suture the scalp. Animals were allowed to recover on a heating pad until mobile, at which point they were returned to their home cage. Sham animals underwent all surgical procedures including attachment to the FPI device with exclusion of the actual fluid pulse.

\section{PV-IN cell counting}

To show changes (if any) in number of PV-Tomato interneurons resulted from TBI, sham and LFPI mice (7 d after injury) were deeply anesthetized with $5 \%$ chloral hydrate and perfused with $15 \mathrm{ml}$ of saline followed by $50 \mathrm{ml}$ of paraformaldehyde (4\% in phosphate buffer, $\mathrm{pH} 7.4$; Sigma-Aldrich). The brains were removed and postfixed in the fixative for $90 \mathrm{~min}$. Vibratome slices were cut at $50 \mu \mathrm{m}$ in thickness with a VT 1000 S (Leica) and collected in serial from a fixed brain. The slices were treated with $0.3 \%$ Triton $\mathrm{X}-100$ for $1 \mathrm{~h}$ at room temperature $(\mathrm{RT})$ and then counterstained with Hoechst, a DNA dye to stain nuclei of all cells in a slice. Hoechst staining (blue) made it easier to outline the structure and boundary of the hippocampus when counting PV-Tomato cells (red) in DG (Fig. 1). Fluorescent images were acquired with an Olympus BX-51 microscope at $10 \times$ magnification. All tdTomato-positive neurons in the DG ipsilateral to the injury site were quantified using modified stereology with the optical fractionator method in which every sixth section through the rostral/caudal extent of the dorsal hippocampus (bregma -1.00 to $-2.75 \mathrm{~mm}$ ) was examined (West et al., 1991; Eisch et al., 2000; Mouton, 2002). Cells were scored as tdTomato-positive if tdTomato labeling in the soma was more intense than background (Lim et al., 2013). Since counting of cells was conducted on every

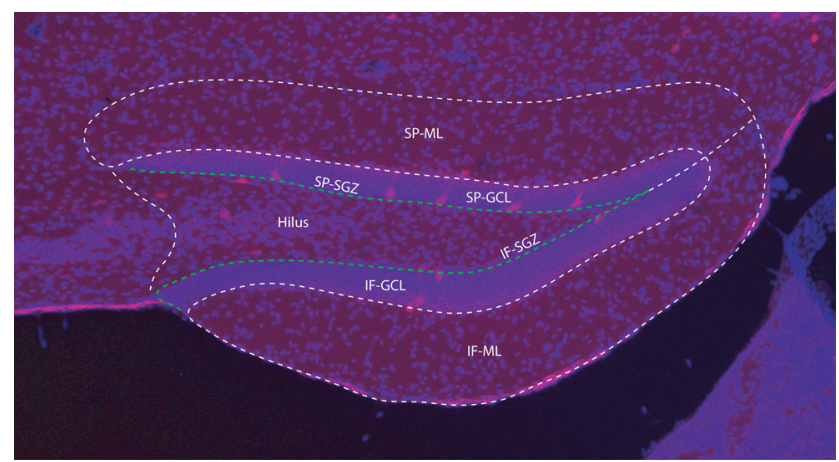

Figure 1. Anatomical layers of the DG used to determine PV+ cell location for counting. Overlay of Hoechst staining (blue) of all cells in the slice was used to identify the anatomic structure and cellular layer boundaries (dotted white line) of the DG when counting tdTomato-expressing (red) PV + cells. Cell anatomic location was divided by both dentate blade, suprapyramidal (SP) or infrapyramidal (IF), and cellular layer, including molecular layer (ML), granule cell layer (GCL), subgranular zone (SGZ), and hilus. TdTomato-expressing cells in the hilus but within one soma length $(20-30 \mu \mathrm{m})$ of the granule cell layer were considered in the subgranular zone (white arrow). Scale bar (lower left): $50 \mu \mathrm{m}$. sixth section of the hippocampus, the number of cells in each anatomic region was multiplied by six to obtain the reported estimate of the total number of cells per region. Cell anatomic location was considered by both dentate blade (suprapyramidal or infrapyramidal) and cellular layer, including molecular layer, granule cell layer, subgranular zone, and hilus. TdTomato-positive cells in the hilus but within one soma length $(20-30 \mu \mathrm{m})$ of the granule cell layer were considered in the subgranular zone (Fig. 1).

\section{Immunofluorescent staining}

To show whether PV-Tomato cells in DG from the transgenic mouse did express PV, we also performed PV immunofluorescent staining on brain slices containing the hippocampus from sham and injured mice. The slices were treated with $0.3 \%$ Triton X-100 and blocked with a mixture of $1 \%$ BSA and $5 \%$ normal goat serum, $60 \mathrm{~min}$, respectively. They were then incubated with a monoclonal antibody against PV (1:1000; Sigma-Aldrich), 60 min at RT and overnight at $4^{\circ} \mathrm{C}$. Visualization was done by incubating the slices with Alexa Fluor 488-conjugated goat antimouse lgG for $75 \mathrm{~min}$ at RT. The immunostained slices were mounted on precleaned slide glass and coverslipped with aqueous mounting medium. In a stained brain slice, PV-immunostained cells showed green and PV-Tomato cells red (Fig. 2). PV-Tomato cells expressing PV should be identified as yellowish to brown, depending on the intensity of tdTomato (red).

\section{Timm staining}

To examine whether mossy fiber spouting existed in the hippocampus, Timm staining was performed according to a protocol reported previously (Van der Zee et al., 1995). Mice were perfused with $15 \mathrm{ml}$ of saline followed by $50 \mathrm{ml}$ of sodium sulfide perfusion medium containing $8.9 \mathrm{~g}$ of $\mathrm{Na}_{2} \mathrm{~S} .9 \mathrm{H}_{2} \mathrm{O}, 10.9 \mathrm{~g}$ of sucrose and $1.19 \mathrm{~g}$ of $\mathrm{Na}_{2} \mathrm{PO} 4 . \mathrm{H}_{2} \mathrm{O}$ dissolved in $100 \mathrm{ml}$ of deionized water (DW). The brains were removed and postfixed in the same perfusion medium for $3 \mathrm{~h}$ at RT. Untreated vibratome slices ( $50 \mu \mathrm{m}$ in thickness) were mounted on gelatin-coated slide glass and air-dried overnight. They were then incubated in dark for $60 \mathrm{~min}$ with a mixture containing 6 volume of gum arabic $(50 \mathrm{~g} / 100 \mathrm{ml})$, 3 volume of hydroquinone $(5.67 \mathrm{~g} / 100 \mathrm{ml})$, and 1 volume of citric acid-sodium citrate buffer $(25.5$ and $23.5 \mathrm{~g}$, respectively, in a total of $100 \mathrm{ml}$ ). For each $100 \mathrm{ml}$ of the incubation solution, $0.5 \mathrm{ml}$ of silver nitrate stock solution (1.7 $\mathrm{g} \mathrm{AgNO}_{3} /$ $10 \mathrm{ml}$ ) was added. Staining was stopped by brief rinse in DW three times. The slices (on glass) were then dehydrated and cleared before coverslipped with Permount. Brightfield microscope was used to observe positive Timm staining. Mossy fiber sprouting (MFS) was defined as Timmstained axonal collaterals (black) present in the molecular layer of DG.

\section{Electrophysiology}

All recordings were made 5-9 d after LFPI or sham surgery. Mice were anesthetized with isoflurane, and the brains were quickly and carefully removed, then placed into ice-cold oxygenated $\left(\begin{array}{llll}95 \% & \mathrm{O}_{2} / 5 \% & \mathrm{CO}_{2}\end{array}\right)$ sucrose 


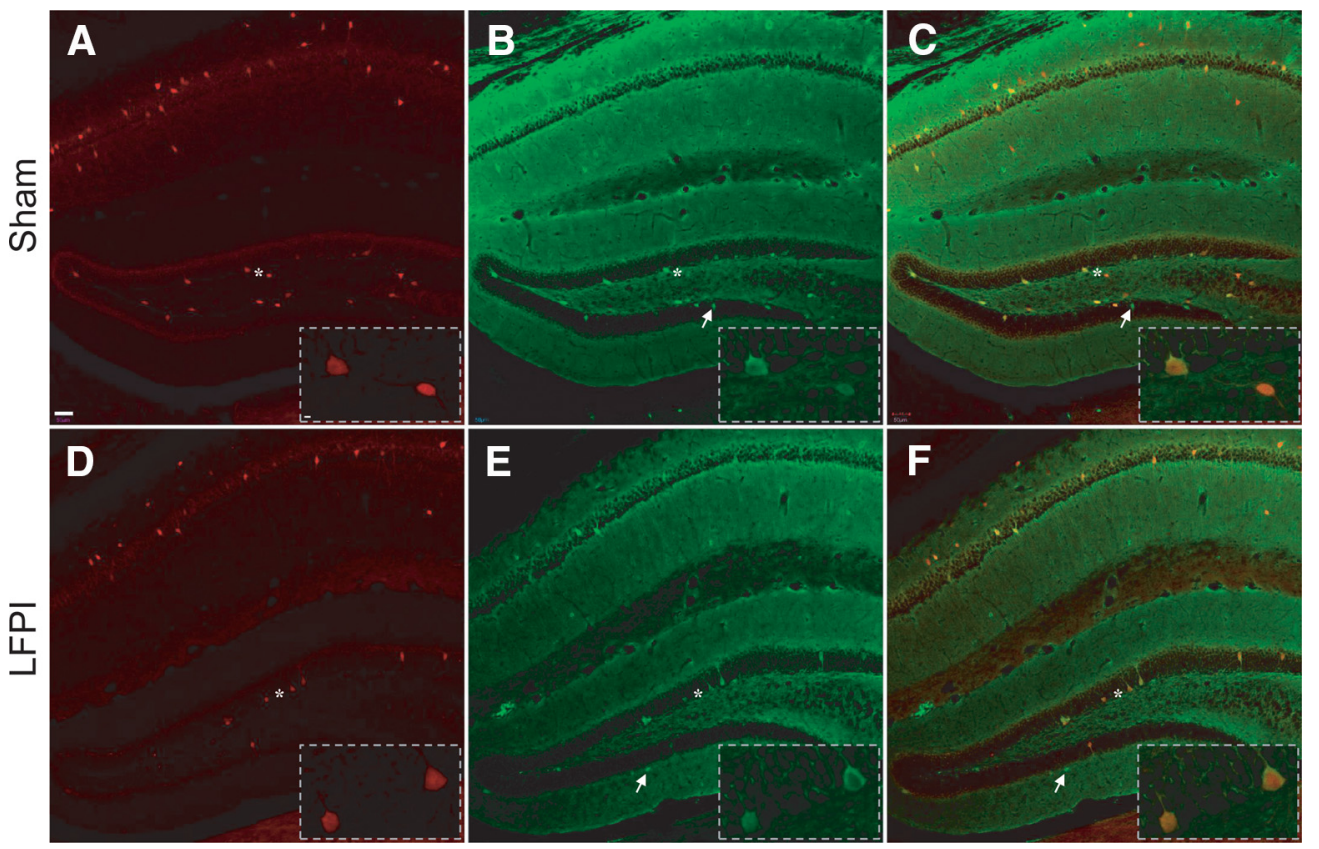

Figure 2. Immunofluorescent staining to confirm dentate PV expression in tdTomato-positive cells in both sham (top row) and LFPI (bottom row) animals $7 \mathrm{~d}$ after surgery. $\boldsymbol{A}, \boldsymbol{D}$, Transgenic expression of tdTomato fluorescence (red) in PV + cells expressing Cre-recombinase. $\boldsymbol{B}, \boldsymbol{E}$, Immunofluorescent staining of PV-expressing cells (green). $\boldsymbol{C}, \boldsymbol{F}$, Co-localization of td-Tomato and immunofluorescence (inset) demonstrates that most td-Tomato-expressing cells are PV+. Asterisk indicates the location of the inset. A small portion of PV-expressing cells (green) did not express td-Tomato (white arrows).

artificial CSF (ACSF) containing the following: $202 \mathrm{~mm}$ sucrose, $3 \mathrm{~mm} \mathrm{KCl}, 1.25 \mathrm{~mm} \mathrm{NaH}_{2} \mathrm{PO}_{4}, 26 \mathrm{~mm} \mathrm{NaHCO}_{3}, 10$ $\mathrm{mm}$ glucose, $1 \mathrm{~mm} \mathrm{MgCl}_{2}$, and $2 \mathrm{~mm} \mathrm{CaCl}$. Coronal slices $350 \mu \mathrm{m}$ thick containing the dorsal hippocampus were cut on a VT1200S vibratome (Leica Microsystems Inc.) and transferred to $33-37^{\circ} \mathrm{C}$ normal ACSF containing the following: $130 \mathrm{~mm} \mathrm{NaCl}, 3 \mathrm{~mm} \mathrm{KCl}, 1.25 \mathrm{~mm} \mathrm{NaH}_{2} \mathrm{PO}_{4}, 26$ $\mathrm{mm} \mathrm{NaHCO}, 10 \mathrm{~mm}$ glucose, $1 \mathrm{~mm} \mathrm{MgCl}$, and $2 \mathrm{~mm}$ $\mathrm{CaCl}_{2}$, for at least $45 \mathrm{~min}$.

\section{Extracellular field recordings}

Electrodes for recordings field EPSPs (fEPSPs) were fabricated from borosilicate glass (World Precision Instruments, \#1B150F-4), pulled to a tip resistance of 2-6 $\mathrm{M} \Omega$ and filled with ACSF. fEPSPs were recorded from an electrode placed in the suprapyramidal molecular layer. Stimulating electrodes were non-concentric bipolar (World Precision Instruments, \#ME12206) and placed at the apex of the molecular layer. Electrical stimuli were 100 $\mu \mathrm{s}$ in duration. Field potential input/output $(\mathrm{I} / \mathrm{O})$ relationships were recorded in response to increasing stimulating intensities (20- to $400-\mu \mathrm{A}$ stimulation, $20-\mu \mathrm{A}$ increments, 8 -s interstimulus interval) from each slice. For each stimulation intensity, recordings were averaged from three trials, and the fEPSP slope was calculated for the first linear portion of the fEPSP (i.e., monosynaptic response). Recordings were obtained with an Axoclamp 900A amplifier and pClamp10 data acquisition software (Molecular Devices; RRID:SCR_011323), filtered at $2 \mathrm{kHz}$. Field potential data were analyzed using pClamp10 software and custom-written scripts in MATLAB R2012b (MathWorks).

\section{Whole-cell patch clamp recordings}

Patch electrodes with resistances of 4-7 M $\Omega$ were pulled from borosilicate glass (World Precision Instruments). Series resistance was monitored throughout the experiment and recordings were discontinued if series resistance exceeded $25 \mathrm{M} \Omega$ at any point. Series resistance was compensated for at $70-80 \%$ compensation. All recordings were made using a Multiclamp 700B (Molecular Devices) sampled at $20 \mathrm{kHz}$, filtered at $2 \mathrm{kHz}$. Electrophysiological data were analyzed using Clampfit 10 and MATLAB software. Synaptic events were determined via the Template Search algorithm in Clampfit 10.

PV-INs were visually identified by fluorescent tdTomato expression in cells within the granule cell layer, subgranular zone, or hilar subregion within $100 \mu \mathrm{m}$ of the hilar-granule cell layer interface. In order to confirm that tdTomato-expressing neurons also had a fast-spiking electrophysiological signature, experiments began with a series of depolarizing current steps. Any neurons that failed to demonstrate non-accommodating trains of APs with a maximum spiking frequency $>30 \mathrm{~Hz}$ (Kawaguchi and Kubota, 1997) in response to depolarizing current injections, or that demonstrated baseline instability, were excluded from further analysis. All whole-cell recordings were performed in one cell per brain slice and are reported as $n$ cells per $n$ mice in each group.

Resting membrane potential was computed as the average voltage in the first $2 \mathrm{~s}$ immediately after whole-cell configuration was achieved. All other intrinsic excitability measures were computed from current clamp recordings 
consisting of a series of 10500 -ms current steps, from -100 to $250 \mathrm{pA}$ in $50-\mathrm{pA}$ increments. Constant holding current was applied to maintain the neuron at $-65 \mathrm{mV}$ before and after current steps. AP threshold was computed by taking $\mathrm{dV} / \mathrm{dt}$ of the voltage trace at $175 \mathrm{pA}$ in the intrinsic excitability experiments and then averaging the corresponding voltage values for the first 10 spikes where dV/ dt exceeded $30 \mathrm{mV} / \mathrm{ms}$ (Howard et al., 2007). Input resistance was determined from the steady-state voltage response for the four initial current steps $(-100$ to $50 \mathrm{pA})$. $\mathrm{AP}$ frequency and corresponding interspike intervals were calculated for all current steps resulting in AP firing.

For whole-cell patch-clamp recording of EPSCs and intrinsic excitability measures electrode internal solution contained the following: $140 \mathrm{~mm}$ K-gluconate, $5 \mathrm{~mm}$ EGTA, $10 \mathrm{~mm}$ HEPES, $1 \mathrm{~mm} \mathrm{MgCl}_{2}, 1 \mathrm{~mm} \mathrm{CaCl} 2,3 \mathrm{~mm}$ $\mathrm{KOH}$, and $2 \mathrm{~mm} \mathrm{Mg}$-ATP and was titrated to a final $\mathrm{pH}$ of 7.1-7.3 with $\mathrm{KOH}$ and osmolality of 290-300 mOsm. Bicuculline methiodide (BMl; $30 \mu \mathrm{M}$, Abcam) was added before voltage clamp recordings, and tetrodotoxin (TTX; $0.4 \mu \mathrm{M}$, Abcam) was added to isolate miniature events (mEPSCs). Neurons were voltage-clamped at $-65 \mathrm{mV}$ for all EPSC voltage-clamp experiments. Liquid junction potential of $16.9 \mathrm{mV}$ (calculated in Clampex) was corrected for in all data reported from these experiments. For whole-cell patch-clamp recording of inhibitory currents, internal solution contained the following: $140 \mathrm{~mm}$ Cs-gluconate, $1 \mathrm{~mm} \mathrm{NaCl}, 5 \mathrm{~mm}$ EGTA, $1 \mathrm{~mm} \mathrm{MgCl}$, $1 \mathrm{~mm} \mathrm{CaCl}$, $3 \mathrm{~mm} \mathrm{KOH}$, and $2 \mathrm{~mm} \mathrm{Mg-ATP}$ and was titrated to a final $\mathrm{pH}$ of 7.2-7.3 with $\mathrm{CsOH}$ and an osmolality of 290-300 mOsm. APV (50 $\mu \mathrm{M}$, Abcam), CNQX (6 $\mu \mathrm{M}$, Abcam), and QX-314 (5 mm, Abcam) were added before voltage clamp recordings, and TTX $(0.4 \mu \mathrm{m})$ was added to isolate mIPSCs. Liquid junction potential of $2.0 \mathrm{mV}$ was corrected for in all data reported from these experiments. Neurons were voltage-clamped at $0 \mathrm{mV}$ for all voltage clamp experiments of inhibitory currents. The slice chamber temperature for all recordings was set to $29-31^{\circ} \mathrm{C}$.

To record perforant path-evoked EPSCs (eEPSCs), a non-concentric bipolar placed in at the apex of the molecular layer was used to stimulate afferent axons onto patch-clamped PV-INs held at $-65 \mathrm{mV}$ in voltage-clamp. Evoked potentials were recorded in response to electrical stimulation from 10 to $100 \mu \mathrm{A}$ in $10-\mu \mathrm{A}$ incremental steps). Three I/O eEPSCs were recorded and averaged from each cell. Extracellular fEPSPs were simultaneously recorded in the molecular layer during evoked voltageclamp and current-clamp experiments and eEPSC for each recorded cell were normalized to the fiber volley amplitude of the slice. As for fEPSP recordings, the first linear, monosynaptic portion of the eEPSC was used to calculate the slope. For current-clamp experiments, an electrode was placed in the perforant path at the apex of the molecular layer. Minimal current stimulation was adjusted to find the lowest current intensity parameter that could elicit at least one AP in a series of 20 stimulations. Once the minimal stimulation current intensity was set, three series of 20 stimulations (12-s interstimulus interval) were administered and the number of stimulus-evoked APs for each series was recorded and reported as a percentage of the total number of stimulations in that series (20 stimulations per series). Throughout currentclamp recordings, a slow injection of current was given to maintain a membrane potential of $-65 \mathrm{mV}$. Stimulusevoked APs were recorded in normal ACSF baseline and then in the presence of $100 \mathrm{~nm}$ picrotoxin (PCTX). Cells were recorded in voltage clamp after PCTX wash-in to confirm that IPSCs were eliminated.

\section{Statistical procedures}

A priori power calculations using $\beta=0.8$ were performed using $\mathrm{G}^{*}$ Power statistical software to determine the minimum sample size required for each experiment (Faul et al., 2007). Electrophysiological and cell count data were analyzed using pClamp 10 and GraphPad Prism 7.0 software (GraphPad Software; RRID:SCR_002798). Data distributions were initially tested for normality using both ShapiroWilk and D'Agostino-Pearson tests. Statistics were performed using either unpaired Student's $t$ test, or two-way repeated measures ANOVA with Sidak's multiple comparison test unless use of another test is indicated (Table 2). In experiments with small sample sizes, effect sizes were reported using Glass's $d$. Cumulative distribution functions of synaptic event properties were constructed by randomly sampling the same number of events $(n=75)$ from each cell. The Kolmogorov-Smirnov (K-S) test was used for statistical comparison of synaptic current measurements. $N$ refers to number of cells and number of animals as described in the results of each experiment. Statistical significance was set at $p<0.05$.

\section{Results}

\section{PV immunostaining confirms td-Tomato expression in $\mathrm{PV}+$ cells}

Cre-tdTomato colocalization was confirmed in a subset of animals (sham $n=3$, LFPI $n=4$ ). Cells were classified as having tdTomato and PV-immunostaining colocalization, PV-immunostaining only, or tdTomato only (Fig. 2). There was no difference in the number of cells where tdTomato and PV-immunostaining overlapped (sham: mean $\pm \mathrm{SD}=78.4 \pm 5.5 \%$ of total cells; LFPI: mean \pm $\mathrm{SD}=78.9 \pm 11.9 \%$ of total cells, $p=0.949$; Table 2 , a). The majority of cells that did not colocalize tdTomato and $\mathrm{PV}+$, were PV + only (sham $=18.5 \pm 5.9 \%$; $\mathrm{LFPI}=13.8 \pm$ $9.7 \%$ total cells), and there was no difference in the number of PV + only cells between sham and LFPI animals $(p=0.47$; Table 2, 1b). The occurrence of tdTomato only cells was extremely rare $($ sham $=3.0 \pm 5.3 \%$; LFPI $=0.99 \pm 1.4 \%$, $p=0.56$; Table 2, 1c) and did not differ significantly between the injury groups. While tdTomato was not expressed in all $\mathrm{PV}+$ cells, this analysis shows that almost all tdTomato cells were PV + and counting tdTomato cells provides a good estimate for PV cell prevalence.

\section{Mild LFPI induces loss of hilar tdTomato-expressing neurons}

Previous studies have found fewer hilar GABA-expressing neurons, including PV-INs, one week after fluid percussion injury; however, these studies used a more 
Table 2: Statistical analysis of experimental results

\begin{tabular}{|c|c|c|c|c|c|}
\hline & Experiment & Data structure & Type of test & Test statistic & $p$ value \\
\hline \multicolumn{6}{|l|}{ Immunostaining } \\
\hline $1 a$ & $\begin{array}{l}\text { Td-Tomato/PV-immunostain } \\
\text { colocalization }\end{array}$ & $\begin{array}{l}\text { Normal } \\
\quad(\text { SW and DP) }\end{array}$ & $\begin{array}{l}\text { Two-tailed unpaired } \\
t \text { test }\end{array}$ & $\begin{aligned} t= & =0.065 \\
\mathrm{df} & =4.42\end{aligned}$ & $p=0.95$ \\
\hline $1 b$ & PV-immunostained cells only & $\begin{array}{l}\text { Normal } \\
\quad(S W \text { and DP) }\end{array}$ & $\begin{array}{l}\text { Two-tailed unpaired } \\
t \text { test }\end{array}$ & $\begin{array}{c}t=0.721 \\
\mathrm{df}=5\end{array}$ & $p=0.47$ \\
\hline $1 \mathrm{c}$ & Td-Tomato cells only & $\begin{array}{l}\text { Normal } \\
\text { (SW and DP) }\end{array}$ & $\begin{array}{l}\text { Two-tailed unpaired } \\
t \text { test }\end{array}$ & $\begin{array}{c}t=0.774 \\
\mathrm{df}=5\end{array}$ & $p=0.56$ \\
\hline \multicolumn{6}{|l|}{ Cell counts } \\
\hline $2 a$ & Total DG & $\begin{array}{l}\text { Normal } \\
\qquad(\mathrm{SW} \text { and DP) }\end{array}$ & $\begin{array}{l}\text { Two-tailed unpaired } \\
t \text { test }\end{array}$ & $\begin{array}{r}t=1.971 \\
\mathrm{df}=15\end{array}$ & $p=0.07$ \\
\hline $2 b$ & Hilus & $\begin{array}{l}\text { Normal } \\
\quad(S W \text { and DP) }\end{array}$ & $\begin{array}{l}\text { Two-tailed unpaired } \\
t \text { test }\end{array}$ & $\begin{array}{r}t=2.431 \\
\mathrm{df}=15\end{array}$ & $p=0.03$ \\
\hline $2 c$ & Subgranular zone & $\begin{array}{l}\text { Normal } \\
\text { (SW and DP) }\end{array}$ & $\begin{array}{l}\text { Two-tailed unpaired } \\
t \text { test }\end{array}$ & $\begin{array}{r}t=1.579 \\
\mathrm{df}=15\end{array}$ & $p=0.14$ \\
\hline $2 d$ & Granule cell layer & $\begin{array}{l}\text { Normal } \\
\text { (SW) }\end{array}$ & $\begin{array}{l}\text { Two-tailed unpaired } \\
t \text { test }\end{array}$ & $\begin{array}{c}t=0.6157 \\
\mathrm{df}=15\end{array}$ & $p=0.55$ \\
\hline $2 e$ & Molecular layer & $\begin{array}{l}\text { Normal } \\
\text { (SW and DP) }\end{array}$ & $\begin{array}{l}\text { Two-tailed unpaired } \\
t \text { test }\end{array}$ & $\begin{array}{c}t=0.9811 \\
\mathrm{df}=15\end{array}$ & $p=0.34$ \\
\hline $2 f$ & Suprapyramidal blade & $\begin{array}{l}\text { Normal } \\
\quad(\text { SW and DP) }\end{array}$ & $\begin{array}{l}\text { Two-tailed unpaired } \\
t \text { test }\end{array}$ & $\begin{array}{r}t=2.048 \\
\mathrm{df}=15\end{array}$ & $p=0.06$ \\
\hline $2 g$ & Infrapyramidal blade & $\begin{array}{l}\text { Normal } \\
\quad(\mathrm{SW} \text { and DP) }\end{array}$ & $\begin{array}{l}\text { Two-tailed unpaired } \\
t \text { test }\end{array}$ & $\begin{array}{r}t=1.117 \\
\mathrm{df}=15\end{array}$ & $p=0.28$ \\
\hline $2 f$ & Septotemporal & Normal (DP) & $\begin{array}{l}\text { Two-way } \\
\text { ANOVA }\end{array}$ & $F_{(1,87)}=0.87$ & $p=0.35$ \\
\hline \multicolumn{6}{|l|}{ Intrinsic properties } \\
\hline $3 a$ & fEPSPs & $\begin{array}{l}\text { Normal } \\
\text { (SW and DP) }\end{array}$ & $\begin{array}{l}\text { Repeated measures } \\
\text { ANOVA }\end{array}$ & $F_{(19,190)}=14.34$ & $p<0.0001$ \\
\hline $3 b$ & Input resistance & Normal (DP) & $\begin{array}{l}\text { Two-tailed unpaired } \\
t \text { test }\end{array}$ & $\begin{array}{c}t=0.3717 \\
\mathrm{df}=18\end{array}$ & $p=0.71$ \\
\hline $3 c$ & Resting membrane potential & $\begin{array}{l}\text { Normal } \\
\quad(\text { SW and DP) }\end{array}$ & $\begin{array}{l}\text { Two-tailed unpaired } \\
t \text { test }\end{array}$ & $\begin{array}{r}t=1.279 \\
\mathrm{df}=18\end{array}$ & $p=0.21$ \\
\hline $3 d$ & AP threshold & Normal (SW) & $\begin{array}{l}\text { Two-tailed unpaired } \\
t \text { test }\end{array}$ & $\begin{array}{r}t=1.244 \\
\mathrm{df}=18\end{array}$ & $p=0.23$ \\
\hline $3 e$ & AP firing frequency & Normal (SW) & $\begin{array}{l}\text { Repeated measures } \\
\text { ANOVA }\end{array}$ & $F_{(1,13)}=0.422$ & $p=0.53$ \\
\hline $3 f$ & AP half-width & Normal (SW) & $\begin{array}{l}\text { Two-tailed unpaired } \\
t \text { test }\end{array}$ & $\begin{array}{r}t=0.612 \\
\mathrm{df}=14\end{array}$ & $p=0.55$ \\
\hline \multicolumn{6}{|l|}{ mEPSCs } \\
\hline $4 a$ & Interevent interval & $\begin{array}{l}\text { Non-normal } \\
\text { (SW and DP) }\end{array}$ & K-S test & $D=0.162$ & $p<0.0001$ \\
\hline $4 \mathrm{~b}$ & Amplitude & $\begin{array}{l}\text { Non-normal } \\
\text { (SW and DP) }\end{array}$ & $\mathrm{K}-\mathrm{S}$ test & $D=0.113$ & $p=0.006$ \\
\hline $4 c$ & Rise $\tau$ & $\begin{array}{l}\text { Non-normal } \\
\text { (SW and DP) }\end{array}$ & $\mathrm{K}-\mathrm{S}$ test & $D=0.104$ & $p=0.004$ \\
\hline $4 d$ & Decay $\tau$ & $\begin{array}{l}\text { Non-normal } \\
\text { (SW and DP) }\end{array}$ & K-S test & $D=0.072$ & $p=0.20$ \\
\hline \multicolumn{6}{|l|}{ eEPSCs } \\
\hline $5 a$ & Slope & $\begin{array}{l}\text { Normal } \\
\text { (SW and DP) }\end{array}$ & Two-way ANOVA & $F_{(1,13)}=0.1825$ & $p=0.68$ \\
\hline $5 b$ & Amplitude & $\begin{array}{l}\text { Normal } \\
\quad(\text { SW and DP) }\end{array}$ & Two-way ANOVA & $F_{(1,22)}=4.715$ & $p=0.04$ \\
\hline $5 \mathrm{c}$ & Charge transfer & $\begin{array}{l}\text { Normal } \\
\quad(\mathrm{SW} \text { and DP) }\end{array}$ & Two-way ANOVA & $F_{(1,21)}=5.426$ & $p=0.03$ \\
\hline $5 d$ & $\begin{array}{l}\text { Slope } \\
\text { (BMI wash-in) }\end{array}$ & $\begin{array}{l}\text { Normal } \\
\quad(\text { SW and DP) }\end{array}$ & Two-way ANOVA & $F_{(1,10)}=0.005518$ & $p=0.94$ \\
\hline $5 e$ & $\begin{array}{l}\text { Amplitude } \\
\text { (BMI wash-in) }\end{array}$ & $\begin{array}{l}\text { Normal } \\
\quad(\mathrm{SW} \text { and DP) }\end{array}$ & Two-way ANOVA & $F_{(1,10)}=0.8552$ & $p=0.38$ \\
\hline $5 f$ & Charge transfer (BMI wash-in) & $\begin{array}{l}\text { Normal } \\
\text { (SW and DP) } \\
\text { (Continued) }\end{array}$ & Two-way ANOVA & $F_{(1,10)}=0.9528$ & $p=0.35$ \\
\hline
\end{tabular}


Table 2: Continued

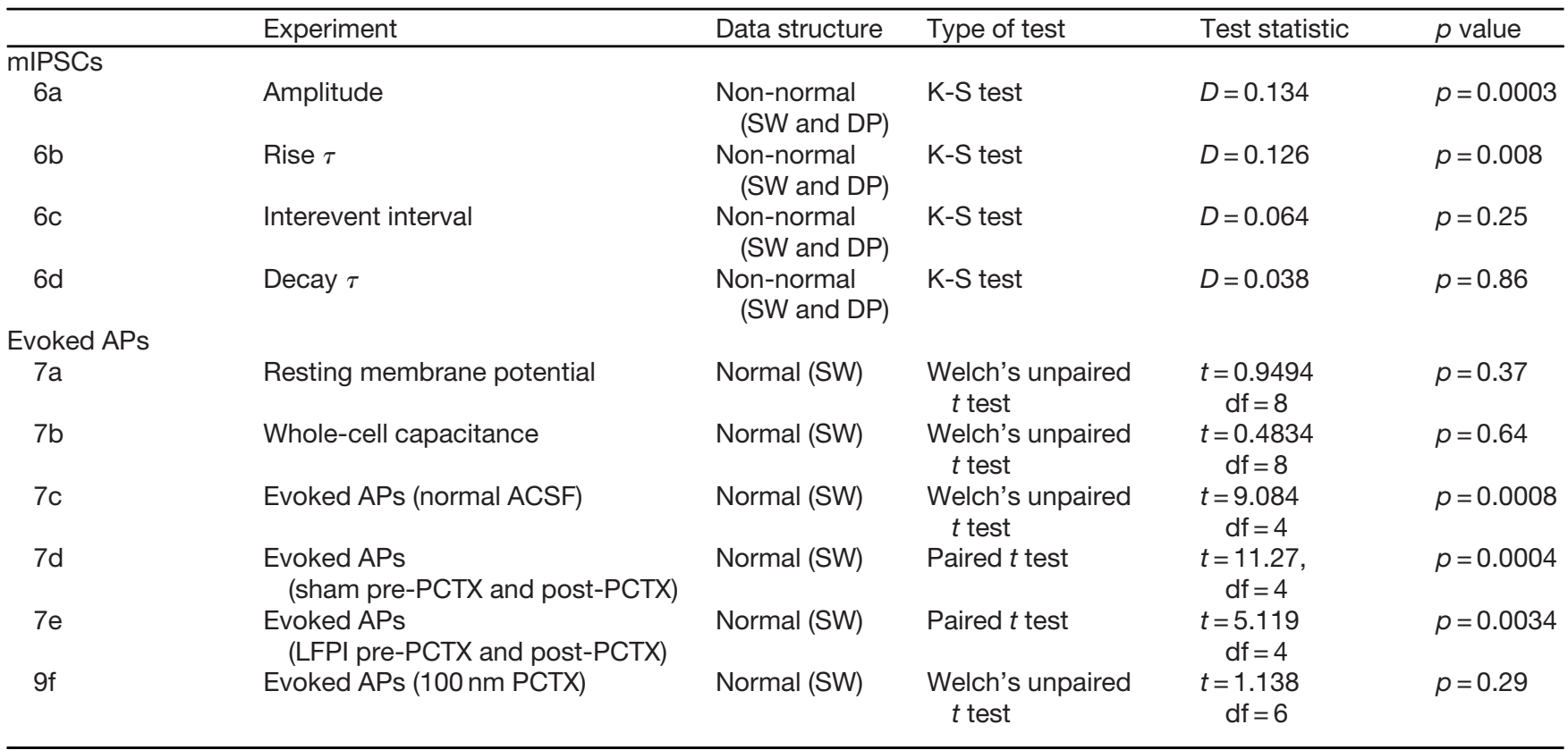

For each experiment (second column), the statistical results included the structure of the data distribution as determined by Shapiro-Wilk (SW) or D'AgostinoPearson (DP) normality tests (third column), the statistical test used, the test statistic and degrees of freedom (df), and the $p$ value; $p$ values $>0.05$ are rounded up to two decimal places. DG, dentate gyrus; PCTX, picrotoxin.

moderate (2.0-2.2 atm) pressure impact than that implemented in this study (Lowenstein et al., 1992; Toth et al., 1997; Santhakumar et al., 2000; Hunt et al., 2011). Additionally, some studies have observed posttraumatic MFS in the DG molecular layer (Hunt et al., 2011). To test whether hilar PV-IN cell loss occurred in our mild (1.4$1.6 \mathrm{~atm})$ LFPI model, we counted the number of tdTomatoexpressing cells in the dorsal DG ipsilateral to the injury site in sham ( $n=850-\mu \mathrm{m}$ sections per mouse, 8 mice; Fig. $3 A)$ and LFPI ( $n=850-\mu \mathrm{m}$ sections per mouse, 9 mice; Fig. $3 B)$. At one week after injury, the total number of dentate PV-INs appeared to trend downward but did not result in a statistically significant change after injury (sham: mean \pm $\mathrm{SEM}=650 \pm 65$ cells; LFPI mean $\pm \mathrm{SEM}=485 \pm 54$, $p=0.067$; Fig. 3C; Table 2, 2a). However, there were significantly less tdTomato-positive cells in the hilus (sham: mean $\pm \mathrm{SEM}=104 \pm 14$ cells; LFPI mean $\pm \mathrm{SEM}=61 \pm 10$, $p=0.028$; Fig. 3D; Table 2, 2b). PV-IN cell counts remained unchanged in the subgranular zone, granule cell layer, molecular layer, suprapyramidal blade, and infrapyramidal blade when, respectively, counted (Table $2,2 \mathrm{c}-2 \mathrm{~g}$ ). There were no septotemporal differences in PV-IN cell counts (two-way ANOVA, $F_{(1,87)}=0.87, p=0.35$; Table 2, 2f). Furthermore, to examine whether MFS was present in our LFPI model $7 \mathrm{~d}$ after injury, we performed Timm staining to label mossy fiber projections (i.e., granule axons and axon terminals) in the DG ( $n=10$ animals in each group). No Timm-stained fibers were observed in the molecular layer of LFPI (Fig. 3E,F) or sham animals at $7 \mathrm{~d}$ after injury, suggesting that MFS was not present at the time point observed after injury in our LFPI model.

\section{Dentate network hyperexcitability persists in PV-Tomato mouse line}

To ensure that injury alters dentate excitability in our transgenic PV-Tomato mice, I/O curves were generated by electrically stimulating perforant path fibers (stimulation intensity range: $20-400 \mu \mathrm{A}, 20-\mu \mathrm{A}$ increments, 100$\mu$ s duration) and recording extracellular field potentials in the molecular layer one week after LFPI or sham surgery ( $n=6$ mice in each group, three slices per animal) with transgenic animals (Fig. 4A). In brain slices from sham animals, fEPSP slope increased almost linearly as perforant path stimulation intensity increased (Fig. 4B). Slices from LFPI animals demonstrated significantly larger fEPSP slopes with increasing stimulation intensity compared with sham (repeated measures ANOVA, $F_{(19,190)}=14.34$; $p<0.0001$; Table 2, 3a). This injury-induced shift in the I/O curve demonstrates that dentate posttraumatic hyperexcitability is present in the transgenic mouse line used for additional experiments in this study.

\section{PV-IN intrinsic membrane properties are unaffected by injury}

Neuronal intrinsic membrane properties, dictated predominantly by membrane proteins and their subsequent activity, play a significant role in a neuron's propensity to fire APs. After experimental TBI, alterations in intrinsic properties have been observed in dentate glutamatergic neurons (Howard et al., 2007; Gupta et al., 2012). To investigate the intrinsic properties of dentate PV-INs, we performed whole-cell patch clamp recordings one week after LFPI or sham surgery ( $n=10$ cells in each group, one cell per animal; Fig. 4C-G). Passive properties such as membrane input resistance (sham: $92.2 \pm 6.3 \mathrm{M} \Omega$; LFPI: $88.6 \pm 7.5 \mathrm{M} \Omega ; p=0.71$; Fig. $4 D$; Table 2, 3b), and resting membrane potential (mean \pm SEM $=-65.3 \pm 1.4 \mathrm{mV}$ in sham and $-62.9 \pm 1.2 \mathrm{mV}$ in LFPI; $p=0.22$; Fig. $4 E$; Table $2,3 c)$, were not significantly different between cells from sham and LFPI groups. Additionally, PV-IN active firing properties were not affected by injury. PV-INs from sham animals had on average an AP threshold of $-29.8 \pm 1.0 \mathrm{mV}$, 
A

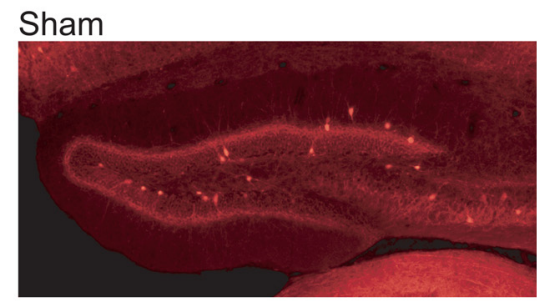

C

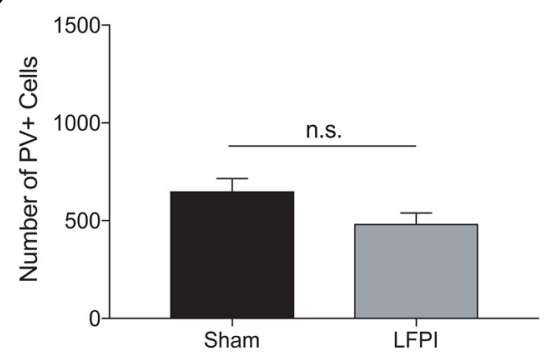

E

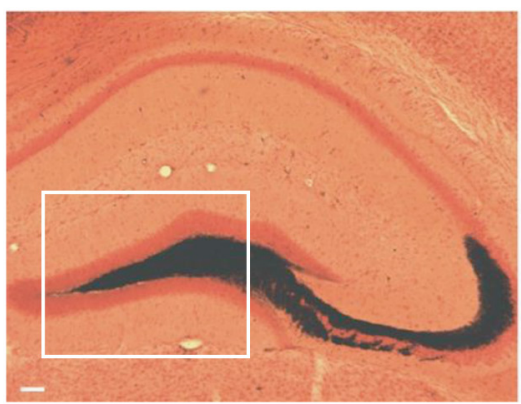

B

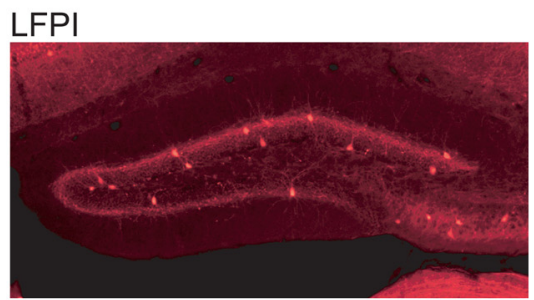

D

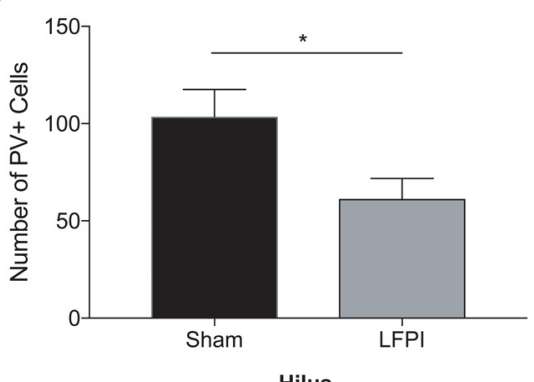

$\mathbf{F}$

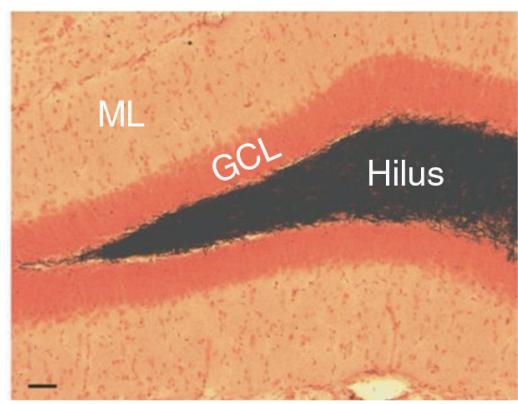

Figure 3. PV-IN cell loss in the dentate hilus occurs one week after mild LFPI. PV+ inhibitory interneurons expressing the fluorescent marker tdTomato in the DG one week after $(\boldsymbol{A})$ sham surgery or $(\boldsymbol{B})$ LFPI. $\boldsymbol{C}$, Total number of PV + cell bodies in the DG are not significantly different between sham and LFPI. $\boldsymbol{D}$, The hilus experiences a significant loss of PV+ interneurons. n.s., non-significant; ${ }^{*} p<0.05$. E, Timm staining of granule cell mossy fiber projections (black) into the hilus and area CA3 in an LFPI animal $7 \mathrm{~d}$ after injury; scale bar: $50 \mu \mathrm{m}$. Inset (white box) magnified in $\boldsymbol{F}$ demonstrates no Timm-stained fibers are present in the inner molecular layer $(\mathrm{ML})$ adjacent to the granule cell layer (GCL) where MFS would occur. Scale bar: $25 \mu \mathrm{m}$.

while cells from LFPI animals had an average firing threshold of $-32.7 \pm 2.1 \mathrm{mV}(p=0.23$; Fig. $4 F$; Table 2, 3d). AP firing frequency in response to depolarizing current steps (400$550 \mathrm{nA}, 50-\mathrm{nA}$ steps) was unaltered by injury (sham: $n=8$ cells, LFPI: $n=7$ cells; repeated measures ANOVA: $F_{(1,13)}=0.42 ; p=0.53$; Figs. $2 G, 4 C$; Table 2, 3e). Lastly, AP half-width, was not significantly different between sham and injured groups (sham: mean $\pm \mathrm{SEM}=0.74 \pm 0.06 \mathrm{~ms}$; LFPI: mean $\pm \mathrm{SEM}=0.69 \pm 0.04 \mathrm{~ms} ; p=0.55$, Table 2, 3f). These findings suggest that there is no net change in either passive or active intrinsic membrane properties of PV-INs after injury.

\section{Excitatory synaptic inputs onto PV-INs exhibit posttraumatic changes}

To examine whether excitatory synaptic input to dentate PV-INs was altered after LFPI, whole-cell voltageclamp recordings of mEPSCs were obtained from sham and LFPI brain slices (sham: $n=7$ cells, 5 animals; LFPI: $n=6$ cells, 6 animals). Representative recordings for each group are shown in Figure 5A. The frequency of mEPSCs was increased in PV-INs after injury as observed by a decrease in interevent intervals [sham: median Inter-quartile range $(\mathrm{IQR})=281$ (640.2) ms; LFPI: median $(\mathrm{IQR})=164$ (436.9) ms, $p<0.0001$, K-S test; Fig. 5B; Table 2, 4a]. Additionally, mEPSC event amplitudes were larger after LFPI [sham: median $(\mathrm{IQR})=30.8$ (19.4) pA; LFPI: median $(\mathrm{IQR})=33.7$ (19.9) pA, $p=0.006$, K-S test; Fig. 5C; Table $2,4 \mathrm{~b}$ ] and had faster rise kinetics [rise $\tau$, sham: median $(\mathrm{IQR})=0.41(0.70) \mathrm{ms}$; LFPI: median $(\mathrm{IQR})=0.32(0.66)$ $\mathrm{ms}, p=0.004$, K-S test; Table 2, 4c]. No change in mEPSC decay kinetics was observed [decay $\tau$, sham: median $(\mathrm{IQR})=0.99$ (2.28) $\mathrm{ms}$, LFPI: median $(\mathrm{IQR})=$ 0.83 (1.92) ms, $p=0.20$, K-S test; Table 2, 4d].

\section{PV-INs receive less feed-forward excitation from the perforant path after injury}

Since local dentate glutamatergic neurons have demonstrated increased activity after experimental TBI (Lowenstein et al., 1992; Santhakumar et al., 2000; Gupta et al., 2012), it is 

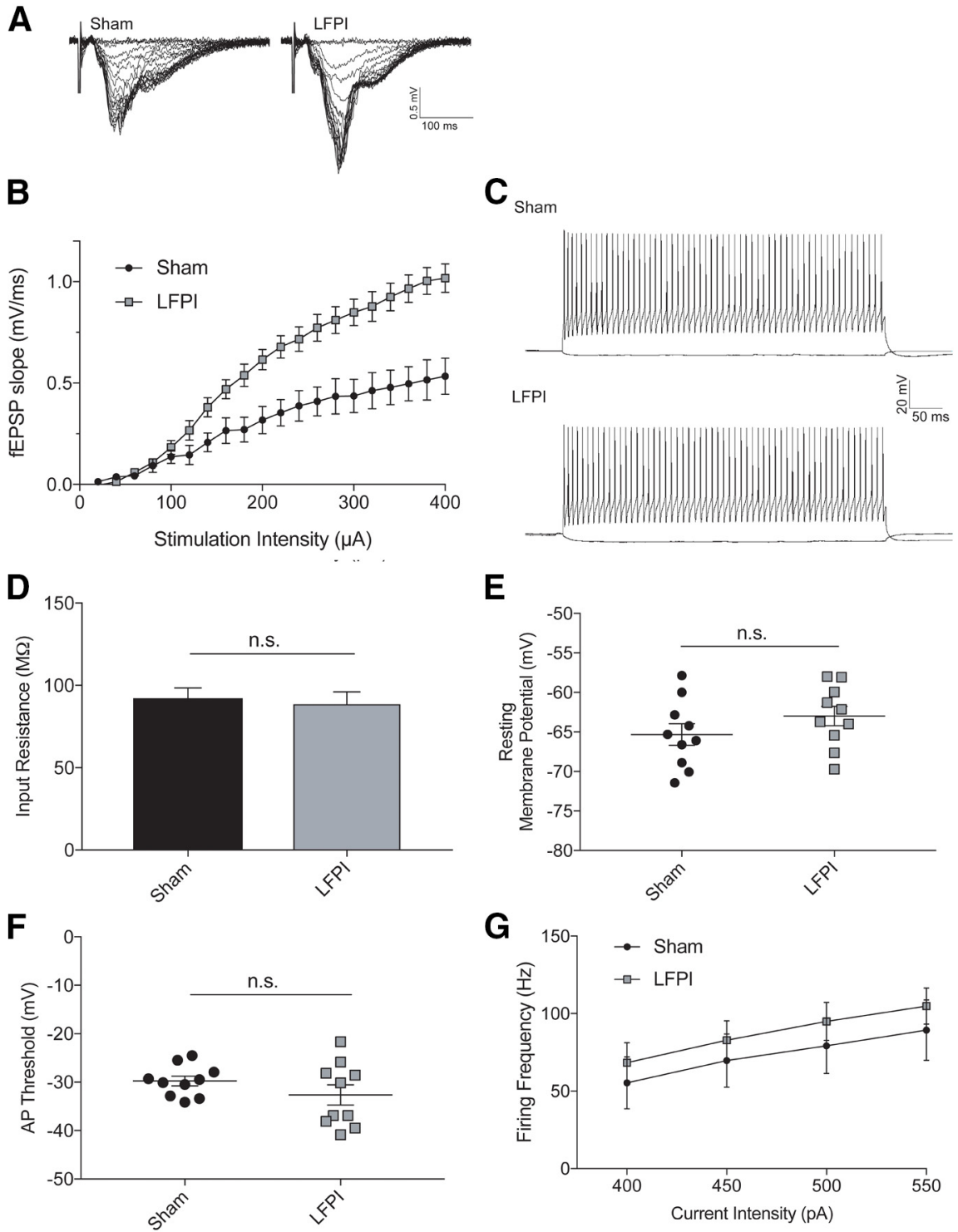

Figure 4. PV-IN intrinsic membrane excitability remains intact after LFPI. $\boldsymbol{A}$, fEPSPs recorded from dentate molecular layer suggests dentate network hyperexcitability in transgenic PV-Tomato mouse line in response to perforant path electrical stimulation as demonstrated by $(\boldsymbol{B})$ significantly larger fEPSP slopes in LFPI mice than sham mice within the stimulation intensity range of 20-400 $\mu \mathrm{A}$, 20$\mu \mathrm{A}$ increments, $100-\mu$ s duration. $\boldsymbol{C}$, Example membrane voltage traces from sham (top trace) and LFPI (bottom trace) PV-INs in response to $-50 \mathrm{pA}$ and $+100 \mathrm{pA}$ current injections. Passive membrane properties of PV-INs are unchanged by injury as exemplified by $(\boldsymbol{D})$ membrane input resistance and $(\boldsymbol{E})$ resting membrane potential. Active firing properties also show no significant difference between sham (black points) and injured (gray points) on (F) AP threshold and (G) PV-IN firing frequency in response to increasing depolarizing current injections. n.s., non-significant.

likely that a decrease in AP-mediated excitatory drive is coming from perforant path synapses. To test the effect of injury on feed-forward excitation of PV-INs, we examined the I/O relationship of eEPSCs by electrical stimulation of the perforant path at incremental stimulus intensities (10-100 $\mu \mathrm{A}$; Fig. $6 A$, top row). While the slope of perforant path eEPSCs was not significantly different between PV-INs from sham $(n=12$ cells, 6 animals) and injured ( $n=11$ cells, 6 animals; repeated measures ANOVA, $F_{(1,13)}=0.1825, p=0.68$; Fig. $6 B$, left; Table 2, 5a), there was a decrease in eEPSC amplitude repeated measures ANOVA, amplitude: $F_{(1,22)}=4.715$, $p=0.041$; Fig. $6 B$, middle; Table 2, 5b) and charge transfer with increasing stimulus intensities $\left(F_{(1,21)}=5.426, p=0.029\right.$;
Fig. 6B, right; Table 2, 5c). BMI was then washed in to block local GABAergic inhibition onto cells in sham and LFPI slices, respectively, and evoked synaptic current properties were re-examined (Fig. 6A, bottom row). In the absence of inhibition, LFPI eEPSC I/O curves were similar to sham [eEPSC slope: $F_{(1,10)}=0.005, p=0.94$ (Fig. $6 C$, left); eEPSC amplitude: $F_{(1,10)}=0.86, p=0.37$ (Fig. $6 C$, middle); eEPSC charge transfer: $F_{(1,10)}=0.95, p=0.35$ (Fig. $6 C$, right); Table $2,5 d-5 f]$. There was no difference in the passive intrinsic properties of PV-INs used in current clamp experiments (resting membrane potential, sham: mean \pm SEM = $-64.5 \pm 2.6 \mathrm{mV}$; LFPI: mean $\pm \mathrm{SEM}=-61.0 \pm 2.5 \mathrm{mV}$; whole-cell capacitance, sham: mean \pm SEM $=43.4 \pm$ 
A

Sham

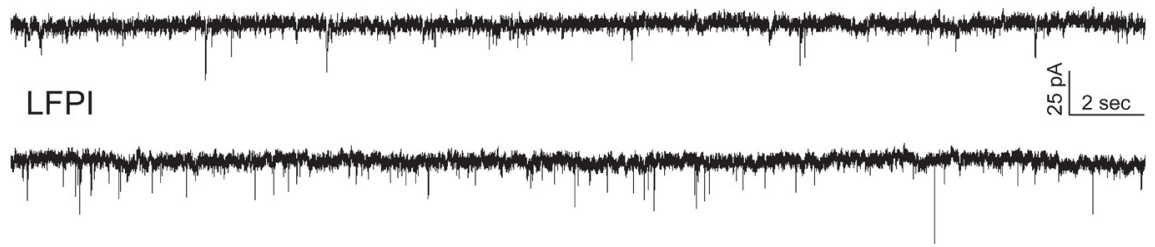

B

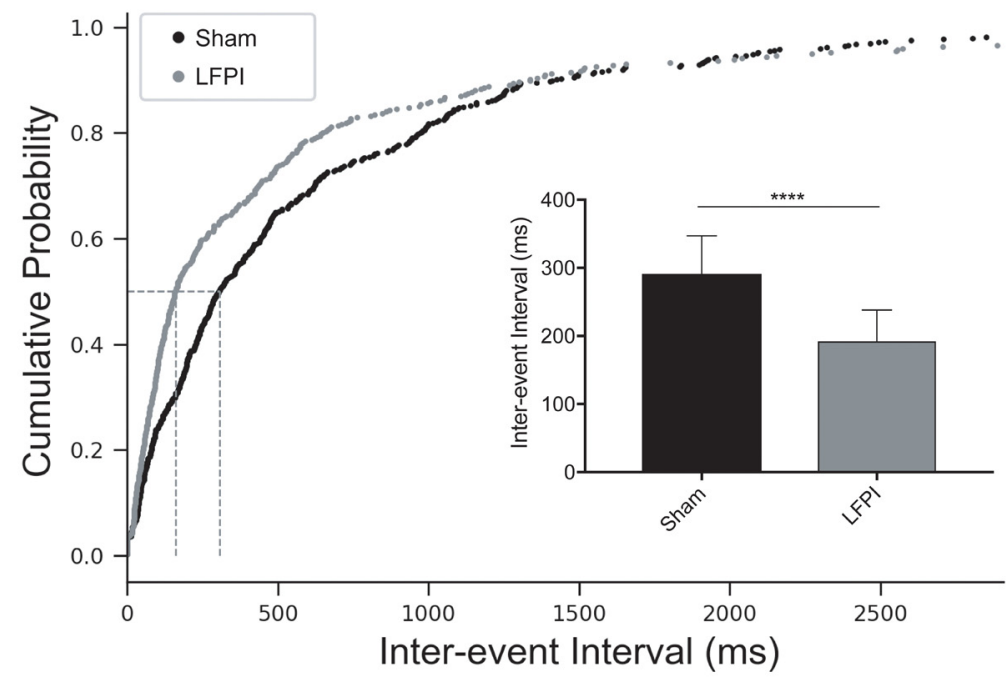

C

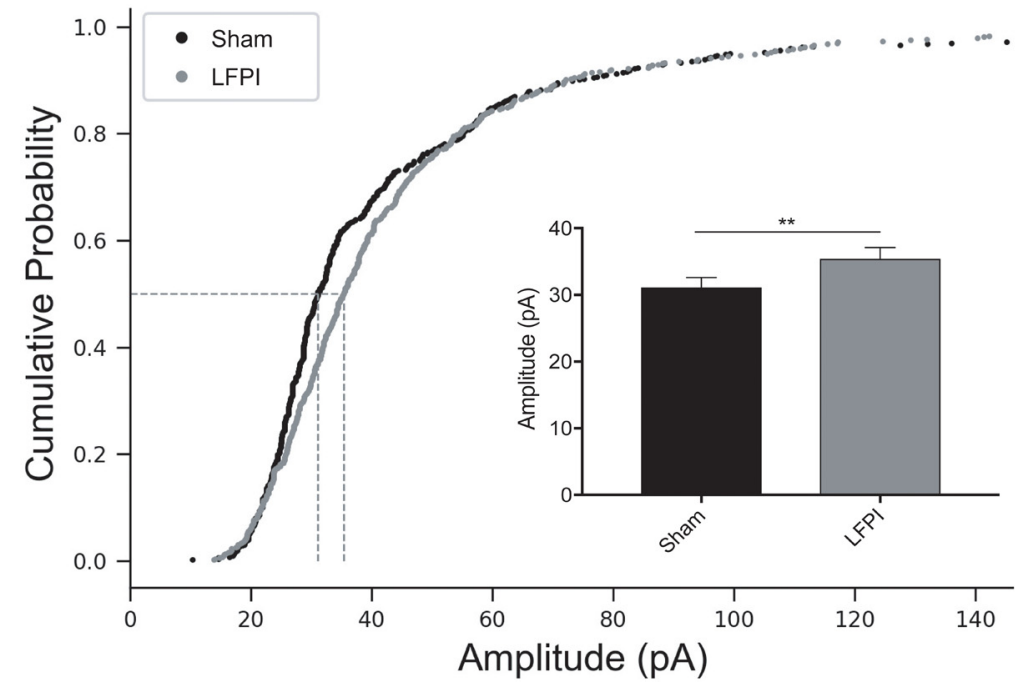

Figure 5. PV-IN mEPSCs are larger and more frequent after LFPI. $\boldsymbol{A}$, Representative traces of voltage-clamp recordings from sham (top trace) and LFPI (bottom trace) PV-IN cells in the presence of $30 \mu \mathrm{M} B M I$ and $0.4 \mu \mathrm{M}$ TTX to block presynaptic AP-dependent synaptic transmission. Cumulative probability plots of $(\boldsymbol{B})$ mEPSC interevent interval and (C) event amplitude from sham PV-INs (black) and LFPI PV-INs (gray). Vertical dashed lines indicate the median of the distribution at probability, $p=0.5$. Insets, Bar graphs of the median and $95 \%$ confidence intervals of $(\boldsymbol{B})$ mEPSC interevent interval and $(\boldsymbol{C})$ mEPSC amplitude in sham (black) and LFPI (gray) PV-INs; ${ }^{\star \star \star \star} p<0.0001,{ }^{\star \star} p<0.01$.

$6.8 \mathrm{pF}$; LFPI: mean $\pm \mathrm{SEM}=43.7 \pm 6.5 \mathrm{pF})$. These data suggest that diminished feed-forward excitatory synaptic transmission from the perforant path onto dentate PV-INs is because of GABAergic inhibition after injury.

\section{Increased synaptic inhibitory input onto PV-INs after LFPI}

To understand how brain injury affects inhibitory synaptic transmission onto dentate PV-INs, we next recorded 
A

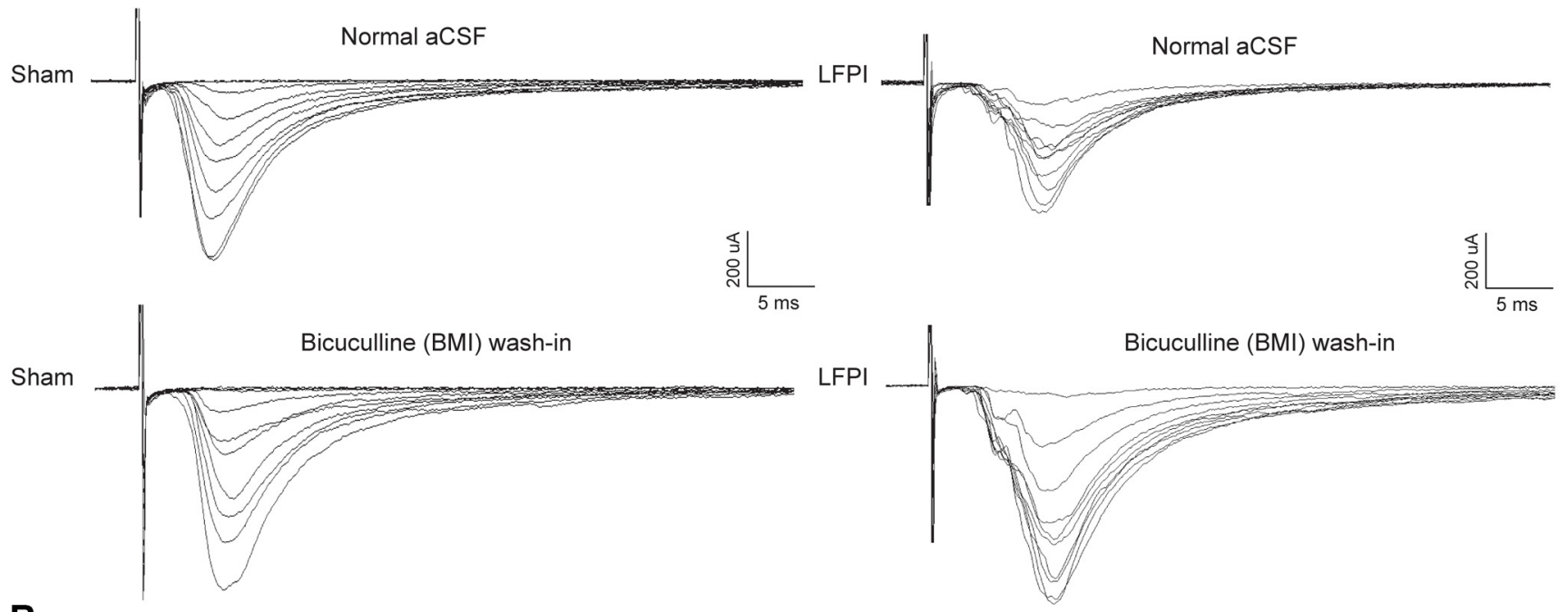

B
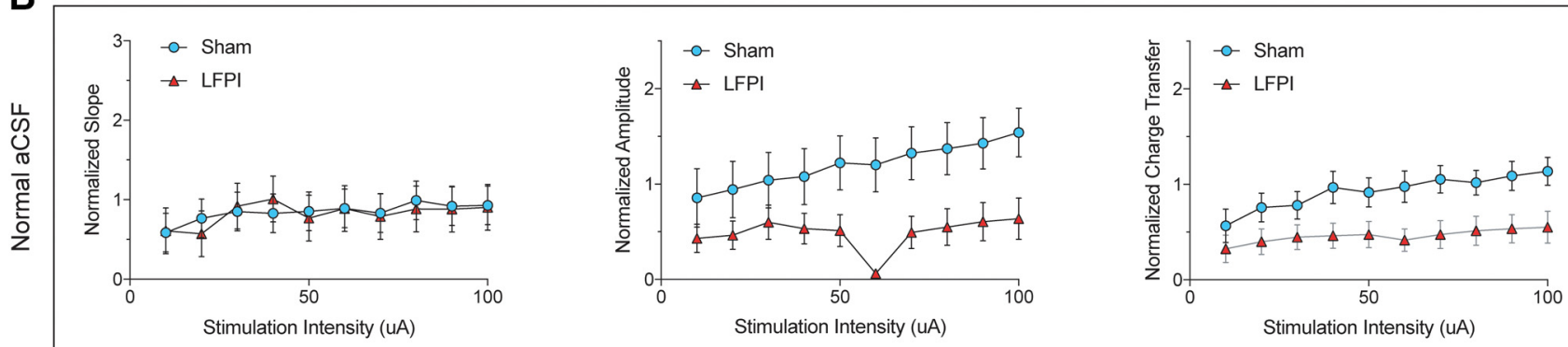

C
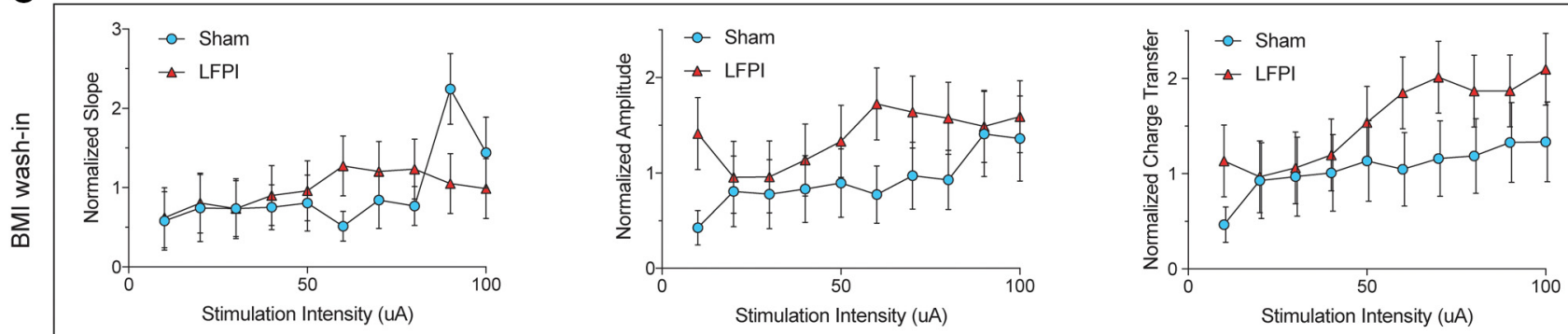

Figure 6. Decreased perforant path-eEPSCs onto PV-INs after LFPI. A, Representative traces of perforant path-eEPSCs onto PVINs from sham (top left), LFPI (top right), and the same sham (bottom left) and LFPI (bottom right) cells with the addition of BMI. eEPSCs were normalized to the fiber volley (FV) amplitude of the extracellular field response of that brain slice. The FV-normalized $(\boldsymbol{B}$, left) slope, (B, middle) amplitude, and (B, right) charge transfer of eEPSCs in sham (blue) and LFPI (red) PV-INs. FV-normalized (C, left) slope, (C, middle) amplitude, and (C, right) charge transfer of eEPSCs after BMI wash-in.

miniature AP-independent inhibitory events (mIPSCs; sham: $n=6$ cells/animals, LFPI: $n=7$ cells/animals; Fig. $7 A)$. We observed an increase in the amplitude of mIPSCs after injury [sham: median $(\mathrm{IQR})=18.3(11.6) \mathrm{pA}$, LFPI: median $(\mathrm{IQR})=19.6(16.8) \mathrm{pA}, p=0.0003$, K-S test; Fig. $7 B$; Table 2, 6a]. Rise kinetics were significantly faster in LFPI PV-INs [rise $\tau$; sham: median $(\mathrm{IQR})=0.73(0.71) \mathrm{ms}$; LFPI: median $(\mathrm{IQR})=0.63(0.75) \mathrm{ms}, p=0.0079$, K-S test; Table 2, 6b]. Injury did not affect mIPSC event frequency however, as the interevent interval between events was not significantly different between PV-INs from sham and injured slices [sham: median $(\mathrm{IQR})=268$ (468.3) ms; LFPI: median $(\mathrm{IQR})=(412.3) 237 \mathrm{pA}, p=0.26$, K-S test; Fig. 7C; Table 2, 6c]. mIPSC decay $\tau$ also remained intact after injury [sham: median $(\mathrm{IQR})=5.6(8.4) \mathrm{ms}$; LFPI: median $(\mathrm{IQR})=7.8$ (9.7) $\mathrm{ms}, p=0.86$, K-S test; Table 2, 6d]. These results demonstrate that $\mathrm{PV}$-INs receive larger $\mathrm{AP}$-independent GABAergic events after LFPI, but that the frequency or ionotropic $\mathrm{GABA}_{A}$-receptor kinetics is unchanged.

\section{Decrease in PV-IN APs is because of net GABAergic inhibition}

The results of the whole-cell patch clamp recordings indicate that there are changes in both excitatory and 
A

Sham

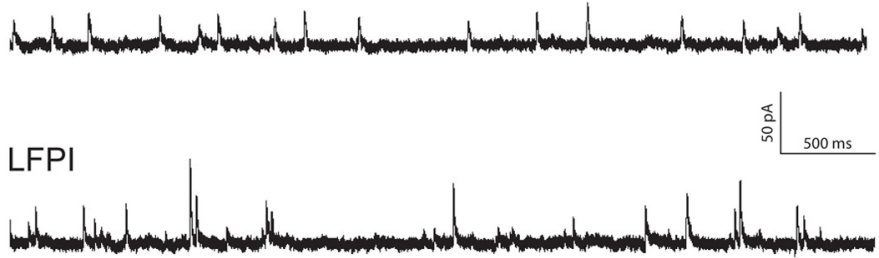

B

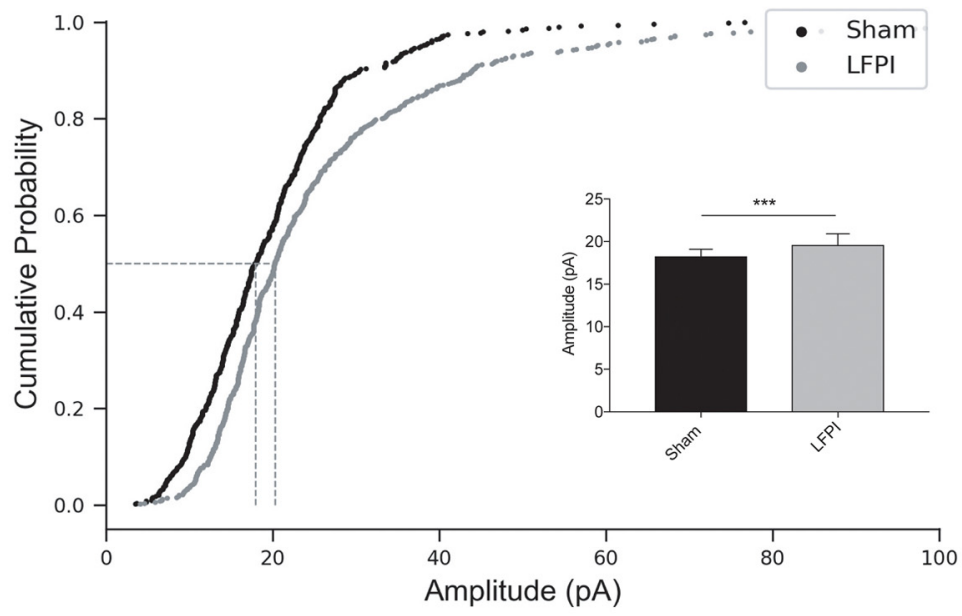

C

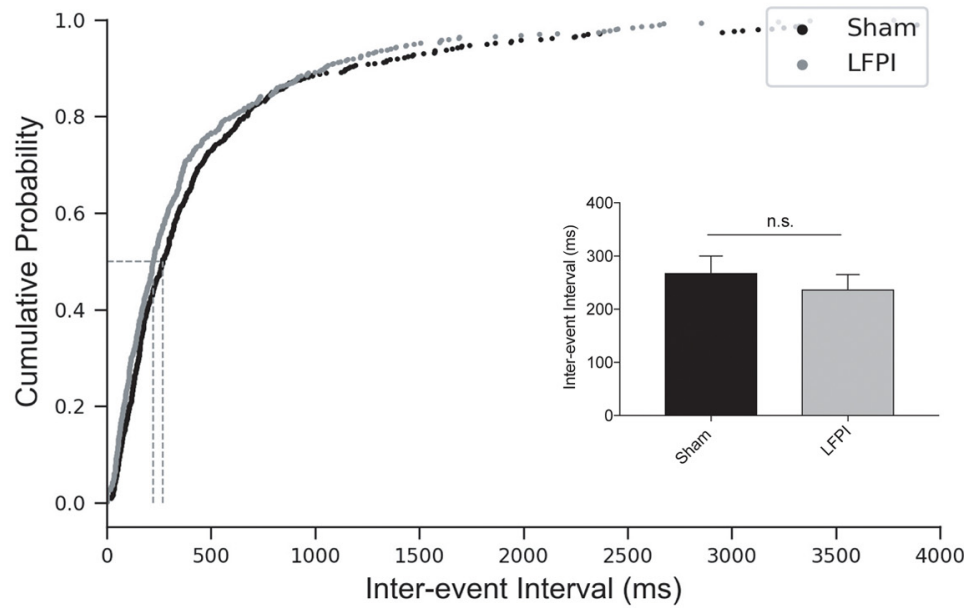

Figure 7. Increase in PV-IN mIPSC amplitude after LFPI. A, Representative traces of voltage-clamp recordings at $0 \mathrm{mV}$ from sham (top trace) and LFPI (bottom trace) PV-IN cells in the presence of glutamatergic blockers, APV and CNQX, and 0.4 $\mu \mathrm{M}$ TTX to isolate action-potential-independent synaptic transmission. Cumulative probability plots of $(\boldsymbol{B})$ mIPSC amplitude, $(\boldsymbol{C})$ interevent interval from sham PV-INs (black) and LFPI PV-INs (gray). Vertical dashed lines indicate the median of the distribution at probability, $p=0.5$. Insets, Bar graphs of the median and 95\% confidence intervals for respective event measurements in sham (black) and LFPI (gray). n.s., no significance; ${ }^{* * *} p<0.001$.

inhibitory synaptic inputs onto PV-INs after brain injury. These alterations affect the synaptic balance of PV-INs and influence the cells' ability to fire an AP by depolarizing or hyperpolarizing the membrane potential. To understand the net effect of posttraumatic synaptic alterations on the feed-forward activation of PV-IN neurons, we performed a series of perforant path minimal stimulation experiments and counted the number of PV-INs evoked APs recorded 


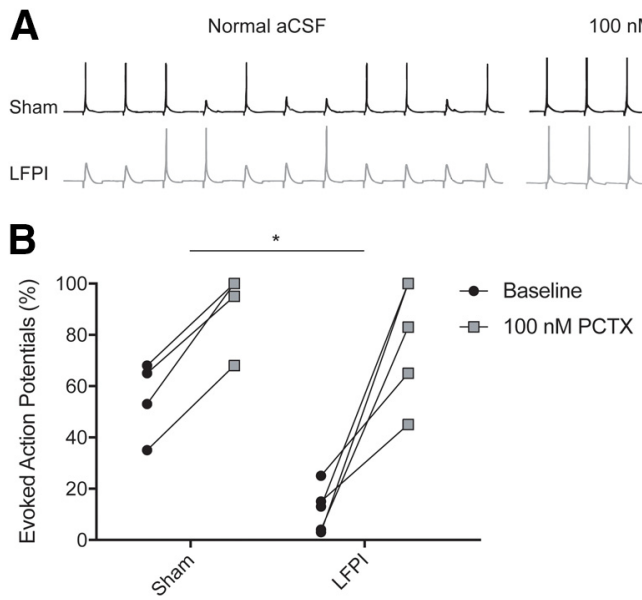

Figure 8. Feed-forward activation of PV-INs is diminished by increased network inhibitory input. $\boldsymbol{A}$, Minimal electrical stimulation evoked voltage responses for individual cells in sham (top left trace) and LFPI (bottom left trace) slices during whole-cell currentclamp recordings with a holding potential of $-65 \mathrm{mV}$ in normal ACSF solution (left) and with bath application of $100 \mathrm{~nm}$ PCTX (sham, right top trace; LFPI, right bottom trace) while recording the same cell with 12-s interstimulus intervals (intervals shorted to 500 ms in figure). $\boldsymbol{B}$, Percentage of evoked APs elicited in response to a sequence of 20 stimulations (i.e., 10 evoked APs in 20 stimulations $=50 \%$ ) at baseline in normal ACSF perfusion solution and after bath application of PCTX. Percent differences in evoked responses for sham (mean \pm SEM): $34.8 \pm 3.1 \%$ ( $n=5$ cells), and for LFPI (mean \pm SEM): $66.6 \pm 13.31 \%\left(n=5\right.$ cells); ${ }^{*} p=0.0008$, Welch's unpaired $t$ test.

in current-clamp ( $n=5$ cells, 5 animals, in each group; Fig. $8 A)$. Before current clamp recording, resting membrane potential and whole-cell capacitance were measured in each cell. Neither resting membrane potential (sham: mean \pm $\mathrm{SEM}=-64.5 \pm 2.67 \mathrm{mV}$; LFPI: mean \pm SEM $=-61.0 \pm$ $2.48 \mathrm{mV}, \quad p=0.37)$ nor whole-cell capacitance [sham: mean $\pm \mathrm{SEM}=43.4 \pm 6.81 \mathrm{pF} ; \mathrm{LFPl}$ : mean $\pm \mathrm{SEM}=43.8 \pm$ $6.48 \mathrm{mV}, p=0.64$, Table 2, 7a,7b] differed between groups. In normal ACSF solution, PV-INs from LFPI slices had a significantly lower percentage of evoked APs than cells from sham slices (\% evoked APs, sham: mean \pm SEM $=57.8 \pm$ 6.3\%; LFPI: mean $\pm \mathrm{SEM}=12.0 \pm 4.0 \%, p=0.0008$, Welch's unpaired $t$ test, Glass's $d=3.6$; Fig. $8 B$, black circles; Table 2, 7c). There was no difference between the baseline stimulation levels of sham and LFPI groups (sham: mean \pm SEM $=44 \pm 21.6 \mu \mathrm{A}$; LFPI: mean $\pm \mathrm{SEM}=50 \pm$ $21.7 \mu \mathrm{A}$, two-sample $t$ test $t=-0.19, p=0.85)$. Next, $100 \mathrm{nM}$ PCTX was bath applied to remove $\mathrm{GABA}_{A}$-mediated inhibition from PV-INs. PCTX significantly increased the percentage of evoked APs in both sham (sham pre-PCTX: mean \pm $\mathrm{SEM}=57.8 \pm 6.3 \%$; sham post-PCTX: mean $\pm \mathrm{SEM}=$ $92.6 \pm 6.2 \%, p=0.0004$, paired $t$ test, Table $2,7 d$ ) and LFPI PV-INs (LFPI pre-PCTX: mean \pm SEM $=12.0 \pm 4.0 \%$; LFPI post-PCTX: mean \pm SEM $=78.6 \pm 10.6 \%, p=0.0034$, paired $t$ test, Table 2, 7e). After PCTX application, there was no difference in the percentage of PV-IN evoked APs in sham and LFPI groups (\% evoked APs, sham: mean \pm $\mathrm{SEM}=92.6 \pm 6.2 \%$, LFPI: mean $\pm \mathrm{SEM}=78.6 \pm 10.6 \%$, $p=0.29$, Welch's unpaired $t$ test, Glass's $d=1.13$; Fig. $8 B$, gray squares; Table 2, 7f). These findings demonstrate that feed-forward activation of PV-INs is compromised by network inhibition.

\section{Discussion}

In the DG, GABAergic basket cells and axo-axonic cells (i.e., PV-INs) are important drivers of feedforward inhibition onto granule cells (Kraushaar and Jonas, 2000; Ewell and Jones, 2010). Previous work has shown that feedforward inhibitory control of dentate granule cell firing is compromised after LFPI (Toth et al., 1997; Witgen et al., 2005). In seeking to identify potential cellular sources of granule cell disinhibition, this study is the first to demonstrate altered excitability of dentate PV-INs following experimental TBI. First, we showed that mild LFPI induced a loss of PV-INs in the hilus, recapitulating hilar interneuron loss observed in previous studies using moderate LFPI (Lowenstein et al., 1992; Toth et al., 1997; Santhakumar et al., 2000; Witgen et al., 2005). While surviving PV-INs have normal intrinsic membrane properties, excitatory and inhibitory synaptic currents are, respectively, shifted after injury. Furthermore, the data reveal that cortical feedforward activation of PV-INs is diminished because of a net inhibitory effect and lead to decreased evoked PVIN firing. Together, our findings demonstrate a mechanism of reduced network inhibition contributing to DG and hippocampal dysfunction following TBI.

The observed hilar PV-IN cell loss demonstrates that interneurons in this subregion are vulnerable to cell death in a milder model of LFPI (1.4-1.6 atm). A recent study of mild LFPI in rats also found a non-specific decrease in PV-INs $7 \mathrm{~d}$ after injury (Zhang et al., 2018). The steady number of PV-INs in the subgranular zone and granule cell layers supports findings by Toth and colleagues, who proposed that laminar cell density plays a role in injury-induced neuronal loss, and with loose cell packing in the hilus leading to cell death susceptibility (Toth et al., 1997). An advantage of cell counts in the PV-Tomato transgenic mice used is that fluorescence protein expression is controlled by the CAG promoter and therefore was not directly linked to $\mathrm{PV}$-expression after injury. Therefore, it is unlikely that the decrease in tdTomato-positive cell 
bodies is because of reduced PV protein expression or immunoreactivity (Nichols et al., 2018). However, we cannot rule out that brain injury may negatively affect CAG promotor activation and interfere with fluorescent protein expression.

When we examined the intrinsic membrane excitability of PV-INs, we observed no differences in passive or active properties following injury. Other dentate cells types have also been shown to retain their intrinsic properties, suggesting that the composition of membrane leak and voltage-gated channels are not overtly altered by LFPI (Howard et al., 2007; Santhakumar et al., 2000, 2001). This could reflect homeostatic compensation by opposing modifications of intrinsic currents, as was previously observed in mossy cells after injury (Howard et al., 2007). This is opposed to the transient depolarization found in dentate interneurons because of diminished $\mathrm{Na}^{+} / \mathrm{K}^{+}$ ATPase activity during the early acute postinjury period (i.e., 4 d after FPI; Ross and Soltesz, 2000). Therefore, at $7 \mathrm{~d}$ after injury, homeostatic mechanisms may have recalibrated PV-IN membrane properties. Further inspection of isolated ionic currents may be required to rule out the contribution of compensatory cellular processes of maintaining PV-IN intrinsic excitability and to better understand the dynamicity of cellular properties during the posttraumatic period.

While the intrinsic properties of PV-INs remained intact, changes in both excitatory and inhibitory synaptic currents reflected posttraumatic circuit-level alterations. On the excitatory side, mEPSCs had larger amplitude events, suggesting a larger postsynaptic response (e.g., increased insertion of receptors into the membrane) or larger presynaptic quantal size. The kinetics of mEPSCs were unchanged after injury. Several factors contribute to changes in rise and decay kinetics, including dendritic filtering, glutamate clearance, and receptor subunit composition. The lack of differences in the kinetics of mEPSCs between sham and LFPI groups suggests that factors like glutamate clearance and dendritic filtering may not play a prominent role in integration of EPSCs by PV-INs (Diamond and Jahr, 1997; Magee and Cook, 2000; Williams and Mitchell, 2008). Furthermore, PV-INs in LFPI animals demonstrated increased mEPSC frequency. More frequent mEPSC events may reflect in increased in basal excitatory transmission mediated by changes in release probability or increased presynaptic activity, the latter which has support from previous studies that local dentate glutamatergic neurons are more excitable after injury (Santhakumar et al., 2000; Gupta et al., 2012). This suggests that basal excitatory synaptic transmission onto PV-INs after LFPI may be a consequence of increased local glutamatergic activity in the DG network.

On the inhibitory side, mIPSCs demonstrated larger amplitudes but did not alter their frequency of occurrence, suggesting either an increase in postsynaptic response such as more $\mathrm{GABA}_{\mathrm{A}}$-receptors inserted into the postsynaptic membrane, or the presynaptic packaging of larger GABA quantal sizes. Specifically, enhanced inhibitory events may indicate an increase in tonic GABA-receptor mediated currents, as have been shown in dentate PV-
INs after status epilepticus and granule cells in a controlled cortical impact TBI model (Mtchedlishvili et al., 2010; Yu et al., 2013). Additionally, mIPSCs in LFPI animals had faster rise kinetics than in sham animals. The kinetics of IPSCs at GABAergic synapses are determined by the properties of their postsynaptic receptors. Differences in IPSC kinetics may suggest alterations in the activation or recruitment of $\mathrm{GABA}_{\mathrm{A}}$-receptors with different subunit compositions. Phasic inhibition results are mediated by activation of synaptically located, $\alpha 1$ and $\gamma 2$ subunit-containing postsynaptic receptors by saturating concentrations of GABA. Tonic inhibition results from activation of extrasynaptic $\mathrm{GABA}_{\mathrm{A}}$-receptors containing $\alpha 4$ and $\delta$ subunit-containing by low concentrations of ambient GABA (Rossi and Hamann, 1998; Stell and Mody, 2002; Mody and Pearce, 2004). Extrasynaptic GABA G-re- $^{-}$ ceptors are slow to desensitize while their synaptic counterparts rapidly desensitize. Therefore, it is possible that faster mIPSC rise times suggest alterations in postsynaptic receptor subunit composition.

After LFPI, perforant path-eEPSCs were smaller than sham controls, but returned to sham levels when GABAergic inhibition was blocked by BMl wash-in. No change in eEPSC slopes indicated that the activation of the evoked response was not affected, but the amplitude and overall charge transfer are decreased because of an enhanced inhibitory tone onto PV-INs. Minimal stimulation experiments further demonstrated that net augmentation of GABAergic inhibition decreased PV-INs evoked APs in response to entorhinal afferent input. This finding has major implications for predicting the activity of PV-INs in the posttraumatic DG. It also provides additional evidence that injury-induced granule cell disinhibition may be attributed to decreased activation of feedforward GABAergic sources. While the results of our study do not provide a direct link between altered PV-IN firing and diminished GABAergic synaptic transmission onto granule cells, they do demonstrate network alterations in synaptic transmission that affect the functional activation of PVINs. The posttraumatic decrease in mIPSC frequency onto granule cells seen previously suggests that there are fewer inhibitory synapses onto granule cells, potentially including loss of hilar PV-IN connections (Soltesz et al., 1995; Toth et al., 1997).

At the circuit level, loss of perisomatic inhibitory control of dentate granule cells is likely to disrupt the gating function of the DG after TBI. Additionally, decreased feedforward recruitment of PV-INs could have cognitive consequences. Fuchs and colleagues have previously demonstrated that loss of PV-IN recruitment lead to impaired performance on hippocampal-dependent behavioral task in mice when excitatory drive onto PV-INs was knocked out (Fuchs et al., 2007). Therefore, alterations in PV-IN activation and network recruitment could have profound effects on cognitive processes and potentially underlie hippocampal-dependent cognitive deficits experienced by $\mathrm{TBI}$ patients. Future studies would benefit from investigating potential changes in the properties of PV-IN synapses onto granule cells, as previous work suggests that these synapses may have higher failure rates and 
smaller pools of readily releasable vesicles in a model of dentate network hyperexcitability (Zhang and Buckmaster, 2009).

There are several limitations of this study. It is important to note that perisomatic inhibitory control of dentate granule cells is provided by nonoverlapping populations of $\mathrm{PV}+$ and $\mathrm{CCK}^{+}$basket and axo-axonic cells (Freund and Buzsáki, 1996; Soriano et al., 1990). While this study only examined PV-INs after TBI, understanding the effects of $\mathrm{CCK}^{+}$basket cell inhibition will provide a complete picture of alterations in granule cell perisomatic inhibition. In addition, we did not investigate possible mechanisms of synaptic alterations such as the number of synapses, presynaptic probability of release, or firing activity of presynaptic neurons. Future investigation of the mechanisms of excitatory-inhibitory (E/I) imbalance are crucial to understanding the overall shift in network excitability. Lastly, while both male and female mice were used for experiments, we did not explicitly explore sex as an experimental variable in this study. Previously, our laboratory has demonstrated that female and male mice similarly experience higher fEPSP I/O curves $7 \mathrm{~d}$ after LFPI (citation redacted), however the current study does not explicitly compare sex differences in dentate PV-IN physiology after injury.

In conclusion, our data show that synaptic input onto dentate PV-INs is altered after injury and is associated with diminished afferent activation of PV-INs driven by network inhibition. Inhibition decreases AP initiation and suggests that activation of PV-IN-mediated feedforward inhibition onto granule cells in the DG is compromised following brain injury. These results demonstrate posttraumatic alterations in inhibitory function that may contribute to dentate network hyperexcitability and may hold therapeutic significance in the future as a specific cellular target for restoring hippocampal dysfunction after TBI.

\section{References}

Armstrong C, Soltesz I (2012) Basket cell dichotomy in microcircuit function. J Physiol 590:683-694.

Butler CR, Boychuk JA, Smith BN (2017) Brain injury-induced synaptic reorganization in hilar inhibitory neurons is differentially suppressed by rapamycin. eNeuro 4.

Coulter DA, Carlson GC (2007) Functional regulation of the dentate gyrus by GABA-mediated inhibition. Prog Brain Res 163:235-243.

Diamond JS, Jahr CE (1997) Transporters buffer synaptically released glutamate on a submillisecond time scale. J Neurosci 17:4672-4687.

Eisch AJ, Barrot M, Schad CA, Self DW, Nestler EJ (2000) Opiates inhibit neurogenesis in the adult rat hippocampus. Proc Natl Acad Sci USA 97:7579-7584.

Ewell LA, Jones MV (2010) Frequency-tuned distribution of inhibition in the dentate gyrus. J Neurosci 30:12597-12607.

Faul F, Erdfelder E, Lang A, Buchner A (2007) G*Power 3.1 manual. Behav Res Methods 39:175-191.

Folweiler KA, Samuel S, Metheny HE, Cohen AS (2018) Diminished dentate gyrus filtering of cortical input leads to enhanced area ca3 excitability after mild traumatic brain injury. J Neurotrauma 35:1304-1317.

Freund TF, Buzsáki G (1996) Interneurons of the hippocampus. Hippocampus 6:347-470.

Fuchs EC, Zivkovic AR, Cunningham MO, Middleton S, LeBeau FEN, Bannerman DM, Rozov A, Whittington MA, Traub RD, Rawlins
JNP, Monyer H (2007) Recruitment of parvalbumin-positive interneurons determines hippocampal function and associated behavior. Neuron 53:591-604.

Gupta A, Elgammal FS, Proddutur A, Shah S, Santhakumar V (2012) Decrease in tonic inhibition contributes to increase in dentate semilunar granule cell excitability after brain injury. $\mathrm{J}$ Neurosci 32:2523-2537.

Howard AL, Neu A, Morgan RJ, Echegoyen JC, Soltesz I (2007) Opposing modifications in intrinsic currents and synaptic inputs in post-traumatic mossy cells: evidence for single-cell homeostasis in a hyperexcitable network. J Neurophysiol 97:2394-2409.

$\mathrm{Hu}$ H, Gan J, Jonas P (2014) Fast-spiking, parvalbumin + GABAergic interneurons: from cellular design to microcircuit function. Science 345:1255263-1255263.

Hunt RF, Scheff SW, Smith BN (2011) Synaptic reorganization of inhibitory hilar interneuron circuitry after traumatic brain injury in mice. J Neurosci 31:6880-6890.

Kawaguchi Y, Kubota Y (1997) GABAergic cell subtypes and their synaptic connections in rat frontal cortex. Cereb Cortex 7:476486.

Kraushaar U, Jonas P (2000) Efficacy and stability of quantal GABA release at a hippocampal interneuron-principal neuron synapse. J Neurosci 20:5594-5607.

Lim MM, Elkind J, Xiong G, Galante R, Zhu J, Zhang L, Lian J, Rodin J, Kuzma NN, Pack Al, Cohen AS (2013) Dietary therapy mitigates persistent wake deficits caused by mild traumatic brain injury. Sci Transl Med 5:215ra173.

Lowenstein DH, Thomas MJ, Smith DH, McIntosh TK (1992) Selective vulnerability of dentate hilar neurons following traumatic brain injury: a potential mechanistic link between head trauma and disorders of the hippocampus. J Neurosci 12:4846-4853.

Magee JC, Cook EP (2000) Somatic EPSP amplitude is independent of synapse location in hippocampal pyramidal neurons. Nat Neurosci 3:895-903.

Mody I, Pearce RA (2004) Diversity of inhibitory neurotransmission through GABA(A) receptors. Trends Neurosci 27:569-575.

Mouton PR (2002) Principles and practices of unbiased stereology: an introduction for bioscientists. Baltimore: Johns Hopkins University Press.

Mtchedlishvili Z, Lepsveridze E, Xu H, Kharlamov EA, Lu B, Kelly KM (2010) Increase of GABAA receptor-mediated tonic inhibition in dentate granule cells after traumatic brain injury. Neurobiol Dis 38:464-475.

Nichols J, Bjorklund GR, Newbern J, Anderson T (2018) Parvalbumin fast-spiking interneurons are selectively altered by paediatric traumatic brain injury. J Physiol 596:1277-1293.

Nitz D, Mcnaughton B (2004) Interneurons during exploration of novel environments differential modulation of CA1 and dentate gyrus differential modulation of CA1 and dentate gyrus interneurons during exploration of novel environments. J Neurophysiol 91:863-872.

Ross ST, Soltesz I (2000) Selective depolarization of interneurons in the early posttraumatic dentate gyrus: involvement of the $\mathrm{Na}(+) / \mathrm{K}$ (+)-ATPase. J Neurophysiol 83:2916-2930.

Rossi D, Hamann M (1998) Spillover-mediated transmission at inhibitory synapses promoted by high affinity alpha6 subunit GABA(A) receptors and glomerular geometry. Neuron 20:783-795.

Santhakumar V, Bender R, Frotscher M, Ross ST, Hollrigel GS, Toth Z, Soltesz I (2000) Granule cell hyperexcitability in the early posttraumatic rat dentate gyrus: the "irritable mossy cell" hypothesis. J Physiol 524:117-134.

Santhakumar V, Ratzliff ADH, Jeng J, Toth Z, Soltesz I (2001) Longterm hyperexcitability in the hippocampus after experimental head trauma. Ann Neurol 50:708-717.

Soltesz I, Smetters DK, Mody I (1995) Tonic inhibition originates from synapses close to the soma. Neuron 14:1273-1283.

Soriano E, Nitsch R, Frotscher M (1990) Axo-axonic chandelier cells in the rat fascia dentata: Golgi-electron microscopy and immunocytochemical studies. J Comp Neurol 293:1-25. 
Stell BM, Mody I (2002) Receptors with different affinities mediate phasic and tonic GABA(A) conductances in hippocampal neurons. $J$ Neurosci 22:RC223.

Toth Z, Hollrigel GS, Gorcs T, Soltesz I (1997) Instantaneous perturbation of dentate interneuronal networks by a pressure wave-transient delivered to the neocortex. J Neurosci 17:8106-8117.

Van der Zee CEEM, Rashid K, Le K, Moore KA, Stanisz J, Diamond J, Racine RJ, Fahnestock M (1995) Intraventricular administration of antibodies to nerve growth factor retards kindling and blocks mossy fiber sprouting in adult rats. J Neurosci 15:5316-5323.

West MJ, Slomianka L, Gundersen HJG (1991) Unbiased stereological estimation of the total number of neurons in the subdivisions of the rat hippocampus using the optical fractionator. Anat Rec 231:482-497.

Will TR, Proano SB, Thomas AM, Kunz LM, Thompson KC, Ginnari LA, Jones CH, Lucas SC, Reavis EM, Dorris DM, Meitzen J (2017) Problems and progress regarding sex bias and omission in neuroscience research. eNeuro 4:ENEURO.0278-17.2017.
Williams SR, Mitchell SJ (2008) Direct measurement of somatic voltage clamp errors in central neurons. Nat Neurosci 11:790-798.

Witgen BM, Lifshitz J, Smith ML, Schwarzbach E, Liang SL, Grady MS, Cohen AS (2005) Regional hippocampal alteration associated with cognitive deficit following experimental brain injury: a systems, network and cellular evaluation. Neuroscience 133:1-15.

Yu J, Proddutur A, Elgammal FS, Ito T, Santhakumar V (2013) Status epilepticus enhances tonic GABA currents and depolarizes GABA reversal potential in dentate fast-spiking basket cells. J Neurophysiol 109:1746-1763.

Zhang BL, Fan YS, Wang JW, Zhou ZW, Wu YG, Yang MC, Sun DD, Zhang JN (2018) Cognitive impairment after traumatic brain injury is associated with reduced long-term depression of excitatory postsynaptic potential in the rat hippocampal dentate gyrus. Neural Regen Res 13:1753-1758.

Zhang W, Buckmaster PS (2009) Dysfunction of the dentate basket cell circuit in a rat model of temporal lobe epilepsy. J Neurosci 29:7846-7856. 